\title{
Machine learning approaches for parsing comorbidity/heterogeneity in antisociality and substance use disorders: A primer
}

\section{Empirical Paper}

Cite this article: Shane MS and Denomme WJ. (2021) Machine learning approaches for parsing comorbidity/heterogeneity in antisociality and substance use disorders: A primer. Personality Neuroscience. Vol 4: e6, 1-18. doi: 10.1017/ pen.2021.2

Received: 10 December 2019

Revised: 30 March 2021

Accepted: 12 April 2021

\section{Keywords:}

Externalizing; Antisocial; Substance abuse; Neuroimaging; Machine learning

\section{Author for correspondence:}

Matthew S. Shane,

Email: matthew.shane@ontariotechu.ca

In R. D. Latzman, G. Michelini, C. G. DeYoung, \& R. F. Krueger (Eds.), Novel investigations of the connection between quantitative personality psychopathology models and neuroscience.

\section{Matthew S. Shane (iD) and William J. Denomme}

Ontario Tech University, Forensic Psychology, Oshawa, ON, Canada

\section{Abstract}

By some accounts, as many as $93 \%$ of individuals diagnosed with antisocial personality disorder (ASPD) or psychopathy also meet criteria for some form of substance use disorder (SUD). This high level of comorbidity, combined with an overlapping biopsychosocial profile, and potentially interacting features, has made it difficult to delineate the shared/unique characteristics of each disorder. Moreover, while rarely acknowledged, both SUD and antisociality exist as highly heterogeneous disorders in need of more targeted parcellation. While emerging data-driven nosology for psychiatric disorders (e.g., Research Domain Criteria (RDoC), Hierarchical Taxonomy of Psychopathology (HiTOP)) offers the opportunity for a more systematic delineation of the externalizing spectrum, the interrogation of large, complex neuroimaging-based datasets may require data-driven approaches that are not yet widely employed in psychiatric neuroscience. With this in mind, the proposed article sets out to provide an introduction into machine learning methods for neuroimaging that can help parse comorbid, heterogeneous externalizing samples. The modest machine learning work conducted to date within the externalizing domain demonstrates the potential utility of the approach but remains highly nascent. Within the paper, we make suggestions for how future work can make use of machine learning methods, in combination with emerging psychiatric nosology systems, to further diagnostic and etiological understandings of the externalizing spectrum. Finally, we briefly consider some challenges that will need to be overcome to encourage further progress in the field.

Imagine that a 42-year-old man, diagnosed with antisocial personality disorder (ASPD), psychopathy, and a substance use disorder (SUD), is administered a series of structural, functional, and resting-state brain scans. The results of the scans highlight several potentially important features: reduced hippocampal volume, reduced activity within the anterior cingulate, and reduced connectivity within the default mode network. But what can we conclude from these findings? Do they underlie all of this man's diagnoses? Or just one of them? And if only one - which one? Moreover, do they represent endogenous features of the man's neural environment, which may serve as biomarkers, or as predisposing factors, for these disorders? Or do they instead merely represent the consequences of a lifetime of antisocial behavior and/ or substance abuse? The empirical literature can support either possibility: those at risk for externalizing disorders do show unique neural features that appear to predate their problematic behavior (Nguyen-Louie et al., 2018); likewise, participation in an antisocial lifestyle (Shepherd et al., 2009), or in long-term drug use (Volkow et al., 1992), can have clear, detrimental effects on brain health. However, because as many as $93 \%$ of individuals diagnosed with antisocial personalities also meet criteria for a SUD (Messina et al., 2000; Smith \& Newman, 1990), and because these externalizing constructs are themselves highly heterogeneous (Fanti \& Kimonis, 2017), delineation of the shared/unique features of each disorder has been difficult to achieve. Indeed, despite promises of improved diagnostics and precision psychiatry (e.g., Costafreda et al., 2009; Wium-Andersen et al., 2017), modern clinical neuroimaging has to date been unable to fully unravel the complexity of these and other important questions.

The reasons for these challenges are complex, but are believed to include at least two somewhat related factors. First, while a major goal of clinical neuroimaging has been to use the insights from brain-based inquiries to improve the validity of clinical diagnostic systems, most work to date has used the existing diagnostic categories (i.e., from DSM5 and ICD-10) as the "gold standard" and has referenced their neural findings against these categories. Second, until recently, both sample sizes and computational techniques have been challenged to fully dissect the finer-grained comorbidity and heterogeneity issues inherent in most psychopathology. With regard to externalizing disorders, while considerable work has separately evaluated the neural systems relevant to antisociality and addiction, little neuroimaging work has yet attempted to model the comorbidity between the two (but see Steele et al., 2018), or to extract shared/unique variance in neural outcomes/predictors (but see Abram et al., 2015; Denomme et al., 2018; Hyatt 
et al., 2019). Moreover, despite inherent diagnostic heterogeneity (Brazil et al., 2018; Kotov et al., 2017), most neuroimaging work to date has treated antisocial personalities and SUDs as homogenous groups. This is unfortunate, because it may be through a more detailed understanding of each disorder that a personalized process for the assessment, diagnosis, and treatment of psychiatric disorders will be realized.

Fortunately, solutions for these problems are presenting themselves. First, alternate classification systems, which allow psychopathology to be viewed as dimensional, rather than categorical (e.g., RDoC, HiTOP), are providing an improved structure through which conceptualization of neuropsychiatric disorders can develop (Kotov et al., 2017). Second, a variety of data-driven analysis techniques, including those incorporating machine learning techniques, are becoming increasingly employed to undertake large-scale evaluations of complex psychiatric/neuroscientific relationships (Dwyer et al., 2018; Janssen et al., 2018). In combination with larger datasets and multisite/consortium efforts, these developments are providing methods for deeply interrogating neural systems underlying psychopathology for comorbid relationships, diagnostic heterogeneity, and/or symptom interactions at the neuroscientific and/or phenotypic level (see Bzdok \& MeyerLindenberg, 2018; Rutledge et al., 2019). Work employing these techniques is becoming more common in certain domains (e.g., Alzheimer's: Liu et al., 2014; Moradi et al., 2015; dementia: Mathotaarachchi et al., 2017; Pellegrini et al., 2018; anxiety/depression: e.g., Hilbert et al., 2017), but has only recently begun to percolate through to other psychiatric disorders. Work focused on the externalizing spectrum remains highly nascent.

One reason for this is that personality theory, clinical psychopathology, neuroimaging, and machine learning require highly diverse forms of expertise. With this in mind, the present paper seeks to provide suggestions regarding how data-driven machine learning techniques can be productively merged with dimensional conceptualizations of psychopathology, toward a more comprehensive understanding of the neural systems underlying externalizing disorders. Several recent papers have provided explanations/ tutorials regarding the use of these techniques for psychiatric neuroscience in general (Bzdok \& Meyer-Lindenberg, 2018; Cearns et al., 2019; Durstewitz et al., 2019; Janssen et al., 2018; Rutledge et al., 2019; Woo et al., 2017). Our intent is not to repeat these tutorials, but rather to specifically highlight the potential synergy between these data-driven techniques and developing dimensional nosology for externalizing disorders. We begin by reviewing traditional categorical classification systems and briefly highlighting some of the benefits of emerging dimensional classification systems. Next, we discuss ways through which data-driven machine learning approaches may intersect with these developing nosologies to help drive future insights into both diagnostic and etiological understanding of the externalizing spectrum. We follow this with a review of the modest machine learning work conducted within the externalizing domain to date, and point out areas of strength and weakness within this nascent field. Finally, we provide suggestions for the field, and consider several challenges that will need to be overcome as future work is undertaken.

\section{Categorical Versus Dimensional Classification of Externalizing}

In line with the DSM5's broader classification strategy, Section II defines ASPD and SUD as categorically distinct conditions, each defined by the extent to which an individual meets required criteria. For ASPD, an individual must show significant impairments in both self and interpersonal functioning, as well as antagonistic (e.g., manipulativeness, callousness) and disinhibitory (e.g., irresponsibility, impulsivity, risk-taking) personality traits. For SUD, diagnosis requires the individual to meet at least 2 out of the 11 criteria within a given 12 -month period, including metrics of substance-related physiological reactivity (e.g., withdrawal, tolerance, craving), and/or behavioural and interpersonal consequences of substance use (e.g., social/interpersonal problems; hazardous/irresponsible use). While psychopathy is not officially included within the DSM5, assessment via its most common assessment instrument (the Psychopathy Checklist - Revised; PCL-R, Hare, 1991) has also classically been categorical: individuals score 0,1 , or 2 on each of the 20 criteria (e.g., grandiosity, manipulativeness, lack of empathy, irresponsibility, impulsivity, delinquency), and are assessed as psychopathic via any combination of scoring that reaches at least 30 (out of the possible total of 40).

These classification systems have a long history, and have been seminal in enhancing the reliability of clinical/forensic diagnoses (though see Regier et al., 2013). Moreover, they have stimulated several generations of research into the etiology of psychopathology, and have helped generate the majority of therapeutic regimens in place today. Nonetheless, there are some significant limitations to these categorical approaches that impact their validity (see Insel et al., 2010; Widiger, 1992), and lessen their usefulness for scientific inquiry (see Hopwood et al., 2015; Krueger et al., 2014). First, separation of these externalizing disorders along arbitrary clinical lines hinders the ability to fully investigate known issues of comorbidity and symptom overlap. For instance, several symptoms show common overlap across all externalizing disorders (e.g., social/ interpersonal issues, irresponsibility/risk-taking; Krueger et al., 2002; 2007), suggesting a potentially shared etiological basis. However, the ability to parse disorder-specific variance in symptom presentation, or to evaluate for comorbid interaction effects, is challenging because DSM-based comorbidity levels are so high (Smith \& Newman, 1990).

Second, categorical approaches largely fail to acknowledge known heterogeneity within disorder categories. Both psychopathy and SUD (and to a lesser extent ASPD) can be diagnosed based on highly nonoverlapping sets of symptoms, which all but guarantee considerable within-category differences in symptom characteristics. Psychopathy, for instance, may be diagnosed with or without the presence of core affective or criminogenic traits (Skeem et al., 2007; Yildirim \& Derksen, 2015). Similarly, SUD may be diagnosed with or without the presence of physiological withdrawal symptoms (Denomme et al., 2018; Schuckit et al., 2003). These differences may correspond to further heterogeneity in underlying causal mechanisms (e.g., see Fanti \& Kimonis, 2017), or in the need for individualized treatment responses (see Baskin-Sommers et al., 2015). However, these important distinctions are difficult to identify when diverse individuals are placed within single diagnostic categories (Brazil et al., 2018).

Third, while both psychopathy and DSM5 SUD diagnoses (but not ASPD) do afford some rudimentary consideration of severity, by and large the all-or-nothing nature of existing classification systems affords little ability to separate mild from severe forms of the disorder. All told, these limitations impose downstream limits on scientific work focused on delineating underlying disorder mechanisms (e.g., cognitive, neural, genetic), and on progress toward truly individualized treatment protocols. 
In acknowledgment of these weaknesses, concerted efforts have been placed on developing frameworks that conceptualize functional/dysfunctional states as dimensional, rather than categorical, phenomena. The National Institute of Mental Health has established their Research Domain Criteria (RDoC; Insel et al., 2010), which aim to encourage a bottom-up consideration of the basic building blocks of human functioning; while the Hierarchical Taxonomy of Psychopathology (HiTOP; Kotov et al., 2017) has used an extensive factor-analytic literature to demonstrate a hierarchical structure of psychopathology that can aid the development of an evidence-based dimensional nosology for mental disorders (similarly, the "triarchic model" of psychopathy has extended an empirically derived dimensional approach to the assessment of psychopathic characteristics (e.g., Patrick et al., 2009). Differences between these approaches are important (for instance, $\mathrm{RDoC}$ is a research system that makes no claims (as of yet) to providing formal diagnostic sets, whereas HiTOP is very much aimed at reforming diagnostic systems). However, the key to both efforts is the development of an increasingly dimensional hierarchy, which aims to distance psychiatric diagnosis from mere clinical intuition, and to instead base assessments in empirical patterns of psychological symptom co-occurrence (Conway et al., 2019; Cuthbert \& Insel, 2013; Kotov et al., 2017).

For instance, HiTOP currently uses a six-level hierarchy to conceptualize various psychopathological states, the highest level serving as a placeholder for characteristics common across all psychopathological conditions (e.g., a "p factor"; Caspi et al., 2014), and the lowest level serving to differentiate individual presentations of clinical signs and symptoms (which may be unique to a specific disorder, or common to multiple disorders in varying degrees). Between these anchors, psychopathologies are distinguished by their empirical relationships, with natural variation in underlying processes serving as building blocks for higher-order latent factors. HiTOP does not utilize traditional diagnostic categories per se, but does include these categories within various formulations for a convenient link back to these "historical" diagnoses. For instance, with regard to externalizing disorders, HiTOP currently conceptualizes two higher-order spectra - disinhibited/ antagonistic externalizing - which themselves may relate in differing degrees to substance-abusing and antisocial behaviors (e.g., SUDs vs. ASPD vs. psychopathy vs. other personality disorders), and to specific syndromes/disorders (e.g., Narcissistic/Histrionic/ Paranoid/Borderline), respectively. These constructs and relationships are not written in stone, but rather are intended to serve as a set of malleable, testable hypotheses, which will adjust dynamically to continually mirror the empirically-derived literature.

Some valid critiques of these data-driven approaches have been tabled (e.g., Reed, 2018). However, there appears to be a considerable appetite for considering psychopathological states through the lens of these emerging nosologies. Doing so may not only improve clinical diagnostics and increase scientific utility, but may also afford modelling of disorder comorbidity (by allowing single lower-level features to load differentially on multiple higher-level syndromes), and heterogeneity (by allowing multiple lower-level features to load differentially on single higher-level syndromes (Conway et al., 2019; Cuthbert \& Insel, 2013; Insel et al., 2010; Kotov et al., 2017; Latzman et al., 2020)). For instance, psychopathic individuals who do or do not present with core emotional deficits (see Schmitt \& Newman, 1999) can be modelled independently (see Brazil et al., 2018); or multiple distinct neurobiological risk factors can each serve as independent risk factors for psychopathy (see Brislin \& Patrick, 2019; Patrick et al., 2009), or
SUD (see Koob \& Volkow, 2010; Volkow et al., 2016). Such detailed individualization can in turn allow for better evaluation of underlying mechanisms, and for the development of more individualized treatment interventions.

\section{Hypothesis-Driven Versus Data-Driven Analytic Approaches}

Despite the renewed focus on psychopathological states as dimensional constructs, the majority of translational neuroimaging work on externalizing characteristics continues to use existing clinical categories as organizing features (i.e., DSM5/ICD-10). There may be several reasons for this, but one is the simple computational challenge inherent in analyzing neuroimaging data: most translational neuroimaging work utilizes a standard parametric mapping approach, wherein independent $t$-tests are used to test for changes (in either brain structure or function) at each of $~ 50000$ voxels. Subsequently, to control for ever-present concerns regarding family-wise error rates, a combination of voxel- and cluster-based thresholding procedures are employed to identify significant, reproducible effects. While these methods have been productive overall, they tend to be limited to the interrogation of relatively streamlined analysis models - for instance, hypothesis-driven models that test for linear differences at each voxel. Analyses of this nature are good for testing hypotheses about specific brain-behavior relationships, or specific group-related differences. However, mapping complex multivariate symptom patterns onto similarly complex multivariate brain patterns is not something these analyses were designed to excel at (see Walter et al., 2019).

In recent years, the implementation of increasingly efficient data-driven techniques has made it possible to identify patterns in neuroimaging data structures with increased power and efficiency. In contrast to standard hypothesis testing, wherein a specific a priori hypothesis is evaluated against the null, these data-driven techniques can scour an entire dataset for statistical relationships in a partially (in the case of "supervised" techniques) or completely (in the case of "unsupervised" techniques) model-free manner (see below for definitions of supervised/unsupervised techniques, or for a comprehensive review within the context of psychiatric neuroscience, see Bzdok \& Meyer-Lindenberg, 2018). While classically trained experimentalists will sometimes scoff at this "benefit", by simultaneously evaluating the entire data structure for macro-level patterns, these techniques offer many advantages over traditional analysis techniques, including significantly heightened signal/noise ratios (Bzdok \& loannidis, 2019), reduced need to control for multiple comparisons (Paulus et al., 2019), and an ability to incorporate more complicated multimodal (Sui et al., 2011) and latent factor (Bzdok \& Meyer-Lindenberg, 2019) approaches. Moreover, by allowing findings to reflect the natural structure of the data, rather than presupposed hypotheses regarding symptom disorder clusters, researchers can reduce (though not completely remove; see Paulus et al., 2019; Woo et al., 2017) susceptibility to experimenter bias, and open new avenues for valuable insights (Huys et al., 2016). For instance, rather than a priori separating phenotypic symptoms along pre-defined lines, data-driven techniques can allow natural variation in the data to encourage novel clustering of characteristics (Bzdok et al., 2019; Walter et al., 2019). In the context of externalizing disorders, a data-driven approach may encourage a disruption of traditional diagnostic (i.e., DSM5) and neuroimaging (i.e., modular/ROI analyses) methods, and afford a more bottom-up, data-driven reconceptualization of symptoms/predictors according to empirically-derived variation in psychometric/biometric features. The convergence of these benefits, in combination with the capacity for 
more complicated multimodal/hierarchical models, makes them a logical fit for interrogating nuanced issues of comorbidity and heterogeneity.

Unfortunately, implementation of these data-driven techniques has historically required quite unique expertise, and utilization of these methods in the broad field of personality/psychiatric neuroscience (and the narrower study of externalizing disorders) remains under-represented. Moreover, the majority of work that has been undertaken to date has failed to take full advantage of the power that these machine learning techniques can offer. With this in mind, we describe below several of the more common forms that these data-driven pipelines can take, and provide several specific use cases through which each may have the capacity to facilitate our understanding of the shared/unique variance associated with externalizing symptoms/disorders. Following this, we review the modest body of externalizing work that has employed machine learning methods to date and use this work to highlight potential avenues for future inquiry.

\section{Supervised Versus Unsupervised Approaches}

Data-driven approaches can take two general forms: supervised and unsupervised. Supervised techniques make no assumptions about the data structure or the features to be extracted (i.e., the "independent variables"), but do require that the target being predicted (i.e., the "dependent variable") be user-specified. Supervised techniques have thus become quite popular in psychiatric neuroscience for identifying neural patterns that maximally differentiate patient from control populations. Indeed, supervised pipelines have been used to identify neurobiological features that differentiate healthy controls from a wide variety of patient populations, including patients with schizophrenia (Shen et al., 2010), depression (Zeng et al., 2012), anxiety (Liu et al., 2015), autism (Bi et al., 2018), and Parkinson's disease (Tang et al., 2017). Support Vector Machines (SVMs) are perhaps the most popular architecture used for these purposes, in part because of their ability to remain robust when employed on small samples (Melgani \& Bruzzone, 2004), and in part because of their straightforward differentiation of target groups based on data features that create the most discriminant hyperplane (i.e., the "support vector"; Alpaydin, 2014). While there is no guarantee that the features identified by these data-driven techniques will ultimately have clinical/theoretical relevance, their mere ability to identify features that differentiate patient populations offers potentially important opportunities to improve diagnostic prediction and assessment. However, because the category labels (e.g., DSM5 disease categories) must be defined a priori, most current implementations of supervised models limit their opportunity to motivate truly transformational insights.

That said, there are ways in which supervised models can provide deeper insights into the nature of psychiatric neuroscience in general, and externalizing disorders in particular. For instance, just as supervised models can be used to differentiate patient from control groups, they can also be used to differentiate two or more patient groups. Thus, supervised models can aid differential diagnoses by requesting features that maximally differentiate disorders with known comorbidity or symptom overlap. This has been undertaken with some success in parallel fields (e.g., Du et al., 2015; Hilbert et al., 2017; Rashid et al., 2016), but has seen no uptake for differentiating antisocial personality features from SUDs to date. Alternately, predictive models could be designed to help delineate within-disorder heterogeneity by requesting features that maximally distinguish hypothesized within-disorder subtypes (e.g., relapse/abstinence, greater/lesser severity; Fede et al., 2019; Wetherill et al., 2018). As reviewed later in the paper, a number of studies have used techniques of this nature to begin differentiating based on prognosis or treatment success for psychopathy (Steele et al., 2018), and particularly for SUD (Bertocci et al., 2017; MacNiven et al., 2018); however, much less work has used supervised strategies to distinguish differential symptoms or disorder subtypes. Finally, with slightly adjusted data-driven architecture, supervised models can also be used to test continuous dimensions. For instance, Support Vector Regression (SVR) uses techniques similar to SVM, but is designed to identify a best-fit line that can predict variation in continuous metrics. This may make SVR particularly powerful for melding with dimensional nosology for externalizing disorders, which inherently view psychopathological states as existing on a continuum. Relevant topics for SVR may include the extent to which neural abnormalities track with lifetime substance use burden versus antisocial personality traits (see a similar approach by Denomme et al., 2018); the extent to which time in incarceration serves as an important factor for development or maintenance of different externalizing disorders; or the extent to which specific symptoms (e.g., impulsivity) may relate similarly or uniquely to different externalizing disorders. As with categorical SVM analyses, there remains no guarantee of clinical utility. However, when used in a responsible, datadriven pipeline that includes critical cross-validation strategies (see below for more discussions of this), confidence in the clinical relevance of extracted features/models can be increased considerably.

Unsupervised techniques, in contrast, make no assumptions about the data structure, the features being extracted, or the targets being predicted. The process thus becomes entirely data-driven, with the goal being only to lift out any patterns that emerge reliably from the data structure. As several well-known examples: a) development of the Big Five personality traits benefited greatly from the use of factor analysis, an unsupervised technique that uses blind source categorization to cluster variables based only on their maximum common variance (Goldberg, 1990); and b) identification of the brain's resting-state networks has been greatly facilitated by the use of Independent Component Analysis (ICA; Allen et al., 2011; Beckmann et al., 2005), which has shown considerable utility for the identification and decomposition of statistically independent brain networks based on the grouping of spatially- and/or temporally coherent neural regions (Calhoun et al., 2008). Note that in both of these examples, there was little existing theory available to support specific factor/component structures. Indeed, this is where unsupervised models excel: in identifying statistical patterns that can serve as the basis for theoretical development. To place the utility of this approach in some context, consider an example: a researcher has a group of offenders and wants to evaluate the extent to which variation in neuroimaging features can provide novel information regarding the heterogeneity of the offender population. While a supervised model can be used to identify biomarkers that confirm existing offender categories, an unsupervised model can evaluate the natural variation in the underlying neural patterns and use that variation to generate new categories that may help explain previously unknown features of the population. Thus, when used within a broader pipeline that includes cross-validation procedures, unsupervised models may be viewed as particularly powerful in the early stages of theory building (in contrast to supervised models, which excel at theory confirmation/replication/ extension). A full exposition of these ideas is well beyond the scope of this article, but interested readers may read Maia et al. (2017) for more thoughts regarding the use of data-driven pipelines for theoretical/ atheoretical purposes. 


\subsection{A note on the importance of model validation}

Perhaps the biggest criticism of data-driven methods is their detachment from clinical/theoretical relevance. Indeed, the unconstrained nature of these analytic pipelines allows them to detect any pattern that they can pull from the data, be it signal, noise, artifact, or spurious finding. To counter this, high-quality data-driven pipelines are now compelled to test the resultant model's ability to generalize beyond the tested data. Best practice calls for the use of independent training and testing sets, which are comprised of completely separate samples of participants. Thus, a machine learning model will be trained to maximum predictiveness in training sample A, and then be tested for generalizability in testing sample B. This is a critical step within the machine learning process, to avoid overfitting, and to increase confidence in the reliability/validity of the extracted features. However, the reality is that this requires a sufficient number of participants to construct two independent samples, which is not always possible in psychiatric neuroscience, where access to patient populations and neuroimaging technology can be difficult. As such, other validation methods have been developed, including leave-one-out and k-fold cross-validation techniques, which use variations on bootstrapping procedures to afford validation within a single group of participants. While independent training/testing samples is the gold standard, the goal of each technique is the same: to minimize the likelihood that overfitting of the test data will occur, and to provide a critical demonstration of the potential utility of the model as a predictive device. At this point, some form of cross-validation in machine learning pipelines is essentially mandatory.

\subsection{Multivariate approaches}

The supervised/unsupervised models discussed above all focused on a specific neurobiological feature of interest. However, the computational capacity and enhanced signal/noise ratios of emerging machine learning methods also afford models that incorporate increasingly complex multimodal relationships. This is important, as most research suggests that multivariate models can outperform otherwise equivalent univariate models, with prediction classification rates at times beyond $90 \%$ (Kambeitz et al., 2017). One popular approach for combining multimodal biomarkers of disease states is joint ICA (jICA), which concatenates two or more modalities into a single data stream (Sui et al., 2011). Lottman et al. (2018), for instance, combined measures of gray matter, white matter, cerebrospinal fluid, and the amplitude of low-frequency fluctuations into a single jICA model, toward successful differentiation of first-episode schizophrenia patients and controls (Lottman et al., 2018). Similarly, Ouyang et al. (2015) combined both gray matter volume and white matter functional anisotropy profiles into a single jICA model, toward the identification of multimodal features that distinguished Alzheimer's patients from controls. Combining modalities in this way affords the development of a more comprehensive model, capable of taking into account relationships and unique features of each brain metric. Several studies have employed multimodal neuroimaging pipelines toward the identification of neurobiological differentiators of antisociality (e.g., Steele et al., 2015) and SUDs (e.g., Seo et al., 2015; Whelan et al., 2014). However, the majority of this work, like its unimodal counterparts, has focused solely on identifying neurobiological features that can differentiate patient from control populations, rather than targeting issues of comorbidity/heterogeneity.

Of particular relevance for the present paper is the ability to also merge neuroimaging data with other modalities such as electrophysiological (e.g., Valdes-Sosa et al., 2009), phenotypic (Anderson et al., 2014), and genetic (e.g., Calhoun et al., 2009; Meda et al., 2012) data. Indeed, the process of mapping neurobiological features onto dimensional classifications of psychiatric disorders will almost certainly require a sophisticated merging of personality, clinical, and neurobiological data, to afford unique insights into the multivariate relationships between these constructs (e.g., Hilbert et al., 2017), and to help link biological predispositions to phenotypic characteristics (see Brazil et al., 2018). One particularly interesting method that has shown initial utility combines cross-modal data as simultaneous predictors of psychiatric categories, toward the development of individual phenotypes (i.e., merged neuropsychiatric "fingerprints"; Smitha et al., 2017). Evidence for this type of approach can be seen in Whelan et al. (2014) who successfully combined a wide variety of behavioural, cognitive, personality, environmental, and neuroimaging metrics into a single model to predict binge drinking in at-risk youth (see also Ding et al., 2017). Of relevance to personality-based classification systems like HiTOP, results from this study indicated that neural, environmental, and personality-based features each provided unique explanatory power within the resultant predictive model.

Other applications of multimodal pipelines have used techniques to evaluate for common elements between cross-modal metrics. Zhao et al. (2018), for instance, used unsupervised clustering methods to create neurobiological profiles of autism, ADHD, Alzheimer's, and PTSD/post-concussive syndrome, and subsequently compared the relationship between these profiles and existing clinical and phenotypic metrics of these disorders. Interestingly, while there was a high degree of similarity between the clinical and connectivity metrics for autism and PTSD/postconcussive syndrome, the similarity was higher between phenotypic and connectivity clusters for Alzheimer's and ADHD. Thus, this data provides evidence of a potential disconnect between existing clinical and underlying neurobiological metrics, and also highlights that this similarity/disconnect may vary importantly by disease/dysfunction type. The possibility that similar effects characterize different subclusters of externalizing disorders (e.g., SUD/ ASPD/psychopathy or disinhibitory/antagonistic antisociality) may be of considerable import and remains almost entirely uninvestigated.

\subsection{Latent factor approaches}

Other emerging machine learning methods (e.g., latent factor approaches, hierarchical clustering, deep learning models) have been designed to allow for the modeling of complex hierarchical structures, such that specific lower-order features can be modeled as components of more general higher-order latent factors. Models of this sort can go beyond simple parsing of the neural response patterns between two disorders, and can instead consider the relationship between those disorders in a more sophisticated, ecologically valid manner. For instance, by allowing specific neurobiological characteristics to load simultaneously onto multiple clinical labels, latent factor models can assess the extent to which those characteristics are representative of one specific disorder, or to a broader category of disorders linked by a latent clinical factor. Cha et al. (2016), for instance, used a latent factor approach to delineate shared/unique neurobiological components of Major Depressive Disorder (MDD) and Generalized Anxiety Disorder (GAD; Cha et al., 2016), where comorbidity of symptom characteristics has long been acknowledged (Hamilton et al., 2014). Similar modelling of shared/unique variance has rarely 
been undertaken within the externalizing domain (but see more rudimentary approaches recently undertaken by Denomme et al., 2018; Denomme \& Shane, 2020; Simard et al., 2021), but may be equally informative for distinguishing the extent to which specific neurobiological abnormalities relate to core underlying antisocial characteristics, to consequences of an antisocial/substance-abusing lifestyle, or to shared latent factors. Indeed, HiTOP currently conceptualizes externalizing as composed of two higher-order factors (disinhibited/ antagonistic externalizing), and the triarchic model of psychopathy has conceptualized psychopathy as the higher-order factor of three subdimensions (boldness, meanness, and disinhibition). Within a biobehavioral framework, dimensions of this nature may provide neurobehaviorally-based traits that could serve as intermediary constructs to explain the relationship between psychopathological states (e.g., as conceptualized by HiTOP) and neurobiological underpinnings (e.g., as conceptualized by RDoC; see Perkins et al., 2019 for the elaboration of these ideas). It goes without saying that hierarchical frameworks of this nature will require the employ of hierarchical models to fully test their predictions; that only a handful of machine learning studies on the neurobiological underpinnings of SUD/antisociality have to date taken this approach marks the significant need for additional research.

Alternately, by allowing multiple symptom combinations to load on single disease categories (see Ruiz, Valera, Blanco, \& Perez-Cruz, 2014), issues related to disorder heterogeneity can be increasingly targeted. For instance, some work suggests that SUDs may be conceptualized as occurring with or without withdrawal symptoms (e.g. Denomme \& Shane, 2020). Whereas, DSM5's crude approach classifies all SUD patients together so long as they show some combination of required symptoms, a hierarchical approach that can individually model the prevalence and relevance of each symptom can allow researchers to delve further into these more nuanced questions. Techniques of this nature have demonstrated utility in parallel fields. For instance, Tursich et al. (2015) identified distinct restingstate functional connectivity patterns that delineated hyperarousal and depersonalization components of PTSD (Tursich et al., 2015). Similarly, Drysdale et al. (2017) discovered novel neurophysiological subtypes of depression based on resting-state functional connectivity dynamics. As a result of such differentiation, specific research into course, prognosis, or treatment opportunities may ensue.

Furthermore, work of this nature may afford novel reclassification of disorder types, in line with RDoC and/or HiTOP initiatives. For instance, Van Dam et al. (2017) used factor analysis, in combination with hierarchical clustering, to group a 347-person community sample into "phenotypic communities" based on a combination of behavioral, psychiatric, and resting-state functional connectivity metrics. Techniques of this nature may have considerable significance for externalizing psychopathology, where heterogeneity remains high. For instance, psychopathy is commonly separated via factor analysis into two primary factors and/or four individual facets (interpersonal, affective, behavioral, criminogenic); however, the shared/unique neurobiological components underlying these factors/facets remain poorly understood (see Cohn et al., 2015 for a slightly different neurobiologically motivated delineation). Data-driven techniques that evaluate neurobiological underpinnings via hierarchical clustering, or other latent factor approaches, may achieve important insights into the relationships between these factors/facets, and the extent to which they show shared or unique underlying neurobiological features.

Finally, latent factor structures may facilitate the evaluation of more mechanistically-motivated questions about the relationships between cross-modal constructs (Friston, Redish, \& Gordon, 2017; Meyer-Lindenberg, 2009; Zald \& Lahey, 2017). To this end, neuroimaging metrics may themselves be conceptualized as "intermediate latent factors" within broader computational models that seek to model relationships between factors at different levels of analysis (see Brazil et al., 2018; Perkins, Latzman, \& Patrick, 2019). While only a small amount of work of this nature has been undertaken in psychiatry to date (see Kircanski et al., 2018 as a valuable example), it is more prevalent in other fields - particularly within the Alzheimer's literature where quite advanced work is being undertaken. In perhaps the most sophisticated of these approaches to date, Zhang, Marmino et al. (2016) used a Bayesian model to automatically identify distinct latent factors from atrophy patterns and cognitive deficits in late-onset Alzheimer's disease (AD) dementia patients. These multimodal neural/cognitive latent factors were then used to predict distinct patterns of tau depositions. By placing these metrics as intermediary factors within data-driven models, work of this nature can go beyond searching for potential biomarkers and can instead delve for mechanistic insights into the underlying nature of the disorder. Work of this nature has not yet been pointed toward externalizing disorders, but may offer unique opportunities to differentiate mechanisms related to the antisocial personality, and to substance use/abuse, respectively. For example, as but two possibilities: (a) amygdala volume, connectivity, and sensitivity could be used to form a broader latent "amygdala" factor, which could itself load differentially on subtypes of antisociality; (b) approach and avoidance circuitry could be combined into a "drug-sensitivity" latent factor and used to predict response to drug cues in those with/without withdrawal symptoms.

\section{Existing Work Employing ML Techniques Toward Antisociality and SUDs}

To gain a more comprehensive sense of the state of the field to date, we conducted a meta-search for articles that employed machine learning approaches to predict either antisociality or substance use constructs via neuroimaging metrics. This search elicited 53 studies that met the selection criteria (see Table 1 for a list of these studies, and supplementary methods for all details regarding the meta-search pipeline employed). The majority of these studies have reported moderate-to-high success in predicting clinically relevant features, which speaks to the potential feasibility and utility of the approaches employed (though see Gowin et al., 2019). Nonetheless, work in this area remains nascent, and many opportunities to make full use of data-driven pipelines remain untapped. Below we provide a brief overview of the studies conducted to date, separated by their primary focus on either diagnosis/assessment, prognosis/course, heterogeneity/subtyping, or treatment/rehabilitation. To emphasize the critical importance of validation steps in machine learning pipelines, we discuss below only those studies that included an acceptable form of cross-validation (i.e., leaveone-out cross-validation, $\mathrm{k}$-fold cross-validation, independent training/testing samples).

\subsection{Diagnosis/assessment}

Mirroring somewhat the broader neuropsychiatric literature (see Walter et al., 2019; Woo et al., 2017), the majority of work in the externalizing field to date $(\sim 66 \%)$ has focused on aiding diagnosis/assessment of participants based on the presence/absence of clinically relevant features. In turn, all but one of these studies have employed supervised learning techniques, wherein target categories were provided a priori (e.g., DSM diagnostic categories). 
Classification accuracy has generally been moderate to high (e.g. $65-85 \%$ ) regardless of the neuroimaging modality chosen, including the use of regional cerebral blood flow to predict methamphetamine dependence ( $\mathrm{Li}$ et al., 2019); resting-state functional connectivity dynamics to predict smoking status (Pariyadath et al., 2014; Wetherill et al., 2018), cocaine dependence (Mete et al., 2016; Zilverstand et al., 2018), alcohol use disorder (Zhu et al., 2018) or ASPD diagnosis (Tang et al., 2013a); structural morphology to predict various SUD diagnoses (Mackey et al., 2019), psychopathic traits (Steele et al., 2017) or conduct disorder (Zhang et al., 2019, 2018); diffusor tensor imaging to predict smoking status (Zhao et al., 2019) or; resting-state activity to classify heroin dependence (Zhang et al., 2011), cocaine dependence (Sakoglu et al., 2019), or ASPD (Tang et al., 2013b). Because the vast majority of these studies have focused on a single modality, it is difficult to draw firm conclusions regarding the extent to which the similar classification accuracies suggest shared variance across modalities, or an upper limit on classification. That said, a handful of recent studies have incorporated multiple modalities into their predictive pipeline. In one such study, Ding et al. (2017) distinguished smokers from nonsmokers with $75 \%$ accuracy via multiple resting-state modalities. In the second study, Kamarajan et al. (2020) classified patients with alcohol use disorders with 76\% accuracy via a combination of default mode activity, neurophysiological test scores, and impulsivity levels. Finally, Gowin et al., (2020) compared models with psychosocial metrics, with neuroimaging metrics, or a combined psychosocial/neuroimaging model. While the combined model did show the highest level of prediction (AUC $=.86)$, it only barely outperformed he psychosocial model alone $(\mathrm{AUC}=.84)$. Thus, the extent to which multimodal models will aid diagnostic classification should remain a focus of attention (research from other domains does suggest that incorporation of multiple modalities can aid classification success (Kambeitz et al., 2017)).

Equally importantly, it should be noted that all studies to date have focused on a single disorder category and have sought only to distinguish forensic/psychiatric from healthy populations; thus, the ability to distinguish differential diagnoses, or to model comorbidity, remains almost entirely untested at present. Several studies focused on predicting ASPD diagnoses (Tang et al., 2013a; Tang et al., 2013b) or conduct disorder (Zhang et al., 2019, 2018) did exclude participants based on recent substance abuse, which affords some control over sample variance, and increases the likelihood that the neural features included in the model related to the ASPD/CD diagnoses. Nonetheless, exclusionary practices of this nature still negate the ability to test for comorbid/covariation effects; moreover, given how high substance abuse/conduct disorder comorbidity rates are, generalizability of reported effects may be a concern.

\subsection{Prognosis/course}

Our search identified 10 studies that have to date employed machine learning techniques to predict issues related to prognosis/course of externalizing disorders ( 8 focused on SUD; 2 on antisociality). Unlike most of the studies that have focused on diagnosis/assessment, work in this space has generally taken a quite sophisticated multivariate regressive approach, such that not only neuroimaging data, but also a variety of sociodemographic, personality, clinical, and/or neural predictor variables have been incorporated into a single multimodal predictive model (Clark et al., 2014; Bertocci et al., 2017; Squeglia et al. 2017; Kiehl et al., 2018; Whelan et al., 2014; Spechler et al., 2019). A major advantage of this approach is that it can maximize prediction capacity while also affording measurement of each predictor's unique contribution to the model. However, in order to fully achieve this goal, regressive models must be handled carefully, with predictors stepped into the models in deliberate fashion - in contrast, the majority of studies to date have dumped all predictors into the model simultaneously to achieve the greatest overall prediction levels. In one particularly sophisticated study, Whelan et al. (2014) generated a multivariate model of current and future adolescent alcohol misuse $(n=692)$ to demonstrate that experiential, neurobiological, and personality features each served as unique and important antecedents of binge drinking. Similar approaches by other teams have also utilized multimodal neuropsychosocial models to successfully predict future substance use (Bertocci et al., 2017), future cannabis use (Spechler et al., 2019), and SUD relapse (Clark et al., 2014; Gowin et al., 2015). To repeat, however, these studies generally sought to obtain maximum prediction, rather than to isolate unique variance, thus limiting the ability to model individual predictor/outcome relationships.

More disappointing, none of the eight studies that focused on SUD incorporated any measure of antisociality in their pipeline. As a result, there is currently no way to handle considerations of comorbid relationships. The two studies focused on antisociality (Steele et al., 2015; Kiehl et al., 2018), in contrast, did include measures of substance use/abuse in their pipelines. However, the goal of these studies was again to achieve maximal specificity/sensitivity, and thus issues of comorbidity, or multicollinearity, were not well considered.

\subsection{Heterogeneity/subtyping}

Our search identified five studies (four focused on SUD and one focused on antisocial personality features) that have to date attempted to use machine learning architecture to aid subtyping of externalizing psychopathology. In two of these studies, subtyping was based on symptom severity, with supervised SVMs aiming to categorize individuals with more versus less severe symptom characteristics: Wetherill et al. (2018) attained 88\% accuracy in predicting the severity of nicotine use disorder via within-network connectivity of various resting-state networks, while Steele et al. (2017) reported between $69 \%-80 \%$ prediction accuracy using structural MRI data to categorize adolescents into those with low/high psychopathic traits. Two additional studies used regression-based approaches to predict continuous variation in alcohol use severity (Fede et al., 2019), and years of cocaine use (Joseph et al., 2019), via resting-state functional connectivity metrics. Finally, one additional study, presented as a conference paper took a quite different approach that is worth expanding on here: Zilverstand et al. (2018) combined unsupervised methods with clustering techniques to identify cocaine-dependent and nondependent individuals who showed similar covariation patterns in their resting-state functional connectivity dynamics. Subsequently, the neurocognitive features of participants characterized by each of the resultant connectivity profiles were evaluated and shown to separate individuals with high reward sensitivity from those with low self-control traits. As the only study of its type within the externalizing domain, this study serves as a valuable example of how unsupervised methods can motivate novel reclassifications of clinical constructs, and how the use of neuroimaging metrics as intermediate latent factors can help bridge neurobiological features with behavioral/cognitive phenotypes. 


\subsection{Treatment/rehabilitation}

Our search identified only four studies to date (all focused primarily on SUD) that have employed data-driven techniques to evaluate treatment/rehabilitation success in externalizing populations. The first constituted a rare PET study, which used SVM to demonstrate that resting-state $\mathrm{D} 2 / \mathrm{D} 3$ binding potential in the nucleus accumbens could predict success in a contingency management program (built off of the community reinforcement treatment approach; Higgins and Budney, 1993) with an 82\% accuracy rate (Luo et al., 2014). The second used a cross-validated logistic regression pipeline to predict 3-month relapse rates via functional activity during a drug/food cue reactivity task in a sample of veterans in a 28-day residential treatment program (MacNiven et al., 2018). The third and fourth studies (Yip et al., 2019; Lichenstein et al., 2019) both used a new technique - connectome predictive modeling $(\mathrm{CPM})$ - to together demonstrate that different neural predictors were required to successfully predict cocaine and opioid abstinence rates throughout a 12 -week treatment protocol. While the predictive success of these studies is encouraging, it must be noted that the sample sizes of these four studies $(n=25, n=36$, $n=53$, and $n=53$, respectively), and the diverse nature of neuroimaging metrics employed as predictors, can allow for only the most preliminary of conclusions at present.

The next closest study to evaluate treatment-related success was a functional connectivity study conducted by Steele and colleagues that predicted treatment completion (thus not necessarily success) in a larger sample of stimulant-/heroin abusers $(n=139$; Steele et al., 2018); see also two similar EEG-based studies by the same group that falls outside the scope of this review; Fink et al., 2016; Steele et al., 2014). While both psychopathic traits and dependence status were included as continuous predictors in this study, as with other work from this group, the primary goal was to achieve maximum prediction levels, which led predictors to be included in ways that precluded full evaluation of shared/unique variance. Moreover, while important, work focused on treatment completion cannot speak directly to mechanisms underlying externalizing psychopathology; thus, future work focused more directly on treatment/rehabilitation success would be encouraged.

\subsection{Recommendations for future work}

\subsubsection{Collect data on both addiction and antisociality}

Our search identified only a small number of studies that have considered neuroimaging metrics of both addiction and antisociality in the same machine learning pipeline. Moreover, as described above, because the goal of these studies was generally to achieve maximal prediction of disorder classification, models were not set up in a way to optimize insights into the potential shared/ unique relationships between the identified neural markers and addiction/antisociality. We thus recommend that SUD/antisociality researchers include continuous metrics of both disorders (e.g., psychopathic traits; substance use severity) as standard practice, and that issues of comorbidity/covariation be explicitly evaluated. A small amount of work outside the machine learning literature has moved in this direction. For instance, Denomme et al., 2018 used fMRI to identify regions related to enhanced cue reactivity in cocaine-dependent individuals, and undertook subsequent regression analyses to dissect the extent to which activity within each of these regions related more closely to continuously derived metrics of psychopathic traits (i.e., PCL-R total score) or substance use severity (i.e., years of lifetime use; see also Denomme \& Shane, 2020; Simard et al., 2021). And utilizing a quite distinct approach,
Hyatt et al. (2019) created neuroanatomical profiles (based on their five-factor traits) on 1101 participants from the Human Connectome Project, and reported that while neuroanatomical profiles of Agreeableness and Conscientiousness showed medium-to-large relationships with externalizing psychopathology, neuroanatomical profiles of Agreeableness related more closely to metrics of antisocial behavior, while neuroanatomical profiles of Conscientiousness related more closely to metrics of substance abuse. A valuable next step for the field will be to utilize latent factor models capable of more fully incorporating shared/ unique variance calculations, as well as issues related to comorbidity/heterogeneity.

\subsubsection{More work with dimensional variables}

Most studies have tended to use supervised machine learning techniques (e.g., SVM) that match neuroimaging-based biomarkers to interview-based clinical diagnoses. While valuable, as reviewed above, these categories are themselves inaccurate proxies for the underlying disorder, created through clinical consensus to ensure diagnostic reliability, but not necessarily maximal validity (see Insel et al., 2010; Widiger, 1992). Referring back to these classifications thus poses an inadvertent constraint on any prediction algorithm - moreover, it ensures that data-driven neuroimaging analyses will not improve upon current diagnostic categories.

We thus recommend an increased focus on dimensional constructs that can allow for the identification of novel relationships and new classification strategies (see as example Yip et al., 2018). One way to target issues of comorbidity within a data-driven pipeline would be to combine an algorithmic clustering approach (e.g., ICA) with hierarchical regression, to evaluate the extent to which ICA-extracted neural components load predominantly on ASPD, on SUD, or on a latent externalizing factor. Alternately, employing machine learning techniques that afford prediction of continuous outcomes (e.g., SVR; CPM) would allow researchers to take full advantage of the continuous nature of neuroimaging/psychiatric data, and to evaluate more sophisticated questions regarding the nature of externalizing psychopathology (e.g., disorder severity; treatment success).

\subsubsection{Considering neuroimaging markers as latent intermediate factors}

HiTOP (and to some extent RDoC) encourage consideration of psychological dysfunction within a hierarchical framework; however, the majority of machine learning work to date has failed to take advantage of this hierarchical structure. Zilverstand et al. (2018) is an early exception, as this study incorporated an unsupervised machine learning pipeline to identify neural patterns that were subsequently related not to disorder categories, but rather to dimensional metrics of potentially related neurocognitive functions. This intermediary step of linking neurobiological features to underlying behavior/personality/cognition may be an integral step toward a true mechanistic understanding of disease pathology (Zhao et al., 2018). For instance, if a given neurobiological feature results from substance-induced exogenous factors, then we may anticipate relationships with metrics of substance use severity; if instead a given neurobiological feature results from underlying antisocial characteristics, then we may anticipate relationships with stable personality traits. Alternately, certain features may indeed relate equally to both disorders, and instead map onto a latent externalizing factor. Future work capable of constructing latent factor models will have the ability to interrogate questions 
Table 1. Summary of studies employing machine learning techniques toward evaluation of psychopathy/ASPD and/or substance use disorders

\begin{tabular}{|c|c|c|c|c|c|c|c|c|}
\hline STUDY & $\mathrm{S} / \mathrm{U}$ & $\begin{array}{l}\text { ML } \\
\text { TECHNIQUE }\end{array}$ & MODALITY INVESTIGATED & CV TECHNIQUE & TRAINING SET & $\begin{array}{l}\text { INDEPENDENT TESTING } \\
\text { SET }\end{array}$ & OUtCOME VARIABLE & $\begin{array}{l}\text { PREDICTION ACCURACY } \\
\text { (PA)/OTHER FINDINGS }\end{array}$ \\
\hline \multicolumn{9}{|c|}{ Diagnosis/Assessment } \\
\hline $\begin{array}{l}\text { Amen et al., } \\
2017\end{array}$ & $S$ & LDA & $\begin{array}{l}\text { SPECT - rest and } \\
\text { concentration task }\end{array}$ & LOOCV & 982 CanUD $92 \mathrm{HC}$ & - & CanUD versus $\mathrm{HC}$ & Rest: $92 \%$ PA Task: 90\% PA \\
\hline $\begin{array}{l}\text { Chen et al., } \\
2015\end{array}$ & S & LDA & $\begin{array}{l}\text { Resting-state regional } \\
\text { homogeneity }\end{array}$ & LOOCV & $\begin{array}{l}29 \text { violent juvenile } \\
\text { offenders } \\
28 \mathrm{HC}\end{array}$ & - & $\begin{array}{l}\text { Juvenile violent offenders } \\
\text { versus controls }\end{array}$ & $89.5 \%$ PA \\
\hline $\begin{array}{l}\text { Chung et al., } \\
2018\end{array}$ & S & SVM & fMRI - stop signal task & LOOCV & $\begin{array}{l}40 \mathrm{CD} \\
27 \mathrm{HC}\end{array}$ & - & $C D$ versus $H C$ & $55-66 \%$ PA \\
\hline $\begin{array}{l}\text { Cope et al., } \\
2014\end{array}$ & S & SVM & VBM & LOOCV & $\begin{array}{l}20 \text { homicide offenders } \\
135 \text { non-homicide } \\
\text { offenders }\end{array}$ & - & $\begin{array}{l}\text { Homicide versus non- } \\
\text { homicide offenders }\end{array}$ & $81 \% \mathrm{PA}$ \\
\hline $\begin{array}{l}\text { Ding et al., } \\
2015\end{array}$ & S & SVM & VBM & $\begin{array}{l}10 \text {-fold CV and } \\
\text { Independent sample }\end{array}$ & $\begin{array}{l}60 \text { smokers } \\
60 \text { nonsmokers }\end{array}$ & $\begin{array}{l}28 \text { smokers } \\
28 \text { nonsmokers }\end{array}$ & $\begin{array}{l}\text { Smokers versus. } \\
\text { nonsmokers }\end{array}$ & $\begin{array}{l}\text { Training: } 69.6 \% \text { PA Testing: } \\
64 \% \text { PA }\end{array}$ \\
\hline $\begin{array}{l}\text { Ding et al., } \\
2017\end{array}$ & S & SVM & Multimodal rs-Fmri & 10 -fold CV & $\begin{array}{l}100 \text { smokers } \\
100 \text { non-smokers }\end{array}$ & - & Smokers versus control & $70.5-75.5 \%$ PA \\
\hline $\begin{array}{l}\text { Elton et al., } \\
2014\end{array}$ & S & LDA & Stop-signal fMRI & LOOCV & $\begin{array}{l}26 \mathrm{CD} \\
18 \mathrm{HC}\end{array}$ & - & $C D$ versus control & $89.5 \% \mathrm{PA}$ \\
\hline $\begin{array}{l}\text { Gowin et al., } \\
2020\end{array}$ & S & $\mathrm{RF}$ & $\begin{array}{l}\text { Multimodal } \\
\text { neuropsychosocial }\end{array}$ & 10 -fold CV & $\begin{array}{l}133 \text { binge drinkers } \\
252 \text { nonbinge drinkers }\end{array}$ & $\begin{array}{l}44 \text { binge drinkers } \\
77 \text { nonbinge drinkers }\end{array}$ & Binge versus nonbinge & $\mathrm{AUC}=.64$ \\
\hline $\begin{array}{l}\text { Guggenmos } \\
\text { et al., } 2020\end{array}$ & S & $\begin{array}{l}\text { WeiRD/ } \\
\text { SVM }\end{array}$ & $\begin{array}{l}\text { Multimodal } \\
\text { neuroimaging }\end{array}$ & LOOCV & $\begin{array}{l}119 \mathrm{AD} \\
97 \mathrm{HC}\end{array}$ & - & $A D$ versus $H C$ & 73\%-79\% PA \\
\hline $\begin{array}{l}\text { Guggenmos } \\
\text { et al., } 2018\end{array}$ & S & $\begin{array}{l}\text { WeiRD/ } \\
\text { SVM }\end{array}$ & GM volume & LOOCV & $\begin{array}{l}119 \mathrm{AD} \\
97 \mathrm{HC}\end{array}$ & - & $A D$ versus $H C$ & $\sim 70-74 \%$ PA \\
\hline $\begin{array}{l}\text { Kamarajan } \\
\text { et al., } 2020\end{array}$ & S & $\mathrm{RF}$ & rs-FNC & $\begin{array}{l}\text { Bootstrapped valida- } \\
\text { tion }\end{array}$ & $30 \mathrm{AUD} 30 \mathrm{HC}$ & - & AUD versus $\mathrm{HC}$ & $76.67 \%$ PA \\
\hline Li et al., 2019 & S & SVM & ASL-CBF & $\begin{array}{l}\text { Semi-independent } \\
\text { sample }\end{array}$ & $45 \mathrm{MD} 45 \mathrm{HC}$ & $36 \mathrm{MD}$ same $45 \mathrm{HC}$ & $\mathrm{MD} / \mathrm{HD}$ versus. $\mathrm{HC}$ & $89 \% \mathrm{PA}$ \\
\hline $\begin{array}{l}\text { Luo et al., } \\
2020\end{array}$ & S & SVM & Rs-ALFF & 10 -fold CV & $\begin{array}{l}51 \mathrm{HD} \\
40 \mathrm{HC}\end{array}$ & - & $\mathrm{HD}$ versus $\mathrm{HC}$ & $\sim 64 \% \mathrm{PA}$ \\
\hline $\begin{array}{l}\text { Mackey et al., } \\
2019\end{array}$ & S & SVM & GM volume & Split-half CV & $\begin{array}{l}2140 \text { SUD } \\
1100 \mathrm{HC}\end{array}$ & - & Various SUD versus HC & $\mathrm{AUC}=.43-.78$ \\
\hline $\begin{array}{l}\text { Mete et al., } \\
2016\end{array}$ & S & SVM & SPECT-CBF & LOOCV and 10 -fold CV & $93 \mathrm{CD} 69 \mathrm{HC}$ & - & $C D$ versus. Control & $88 \% \mathrm{PA}$ \\
\hline $\begin{array}{l}\text { Pariyadath } \\
\text { et al., } 2014\end{array}$ & S & SVM & rs-FNC & LOOCV & $\begin{array}{l}21 \text { smokers } \\
21 \text { nonsmokers }\end{array}$ & - & $\begin{array}{l}\text { Smokers versus. non- } \\
\text { smokers }\end{array}$ & $78 \% \mathrm{PA}$ \\
\hline $\begin{array}{l}\text { Park et al., } \\
2018\end{array}$ & S & GAM & $\begin{array}{l}\text { SMRI } \\
\text { DTI }\end{array}$ & 2-fold CV & $\begin{array}{l}34 \text { moderate/heavy } \\
\text { drinkers } \\
671 \text { no/low drinkers }\end{array}$ & - & $\begin{array}{l}\text { Regular versus minimal } \\
\text { drinker }\end{array}$ & 57.4-76.5\% PA \\
\hline $\begin{array}{l}\text { Ruan et al., } \\
2019\end{array}$ & S & SVM & $\begin{array}{l}\text { rs-FNC } \\
\text { SNP }\end{array}$ & Independent sample & $\begin{array}{l}95 \text { drinkers } \\
44 \text { nondrinkers }\end{array}$ & $\begin{array}{l}52 \text { drinkers } \\
21 \text { nondrinkers }\end{array}$ & Drinker versus nondrinker & $\begin{array}{l}\text { Training: } 86.7 \% \text { PA Testing: } \\
71.2 \% \text { PA }\end{array}$ \\
\hline
\end{tabular}




\begin{tabular}{|c|c|c|c|c|c|c|c|c|}
\hline STUdY & $\mathrm{S} / \mathrm{U}$ & $\begin{array}{l}\text { ML } \\
\text { TECHNIQUE }\end{array}$ & MODALITY INVESTIGATED & CV TECHNIQUE & TRAINING SET & $\begin{array}{l}\text { INDEPENDENT TESTING } \\
\text { SET }\end{array}$ & OUtCOME VARIABLE & $\begin{array}{l}\text { PREDICTION ACCURACY } \\
\text { (PA)/OTHER FINDINGS }\end{array}$ \\
\hline $\begin{array}{l}\text { Sakoglu et al., } \\
2019\end{array}$ & S & SVM & rs-FNC & LOOCV & $\begin{array}{l}58 \mathrm{CD} \\
25 \mathrm{HC}\end{array}$ & - & $C D$ versus control & $81-95 \%$ PA \\
\hline $\begin{array}{l}\text { Sato et al., } \\
2011\end{array}$ & S & SVM, MLDA & VBM & LOOCV & $\begin{array}{l}15 \text { PCL-R > } 3015 \text { PCL- } \\
R<30\end{array}$ & - & PCL-R $>30$ versus. $<30$ & $80 \%$ PA \\
\hline $\begin{array}{l}\text { Squeglia et al., } \\
2017\end{array}$ & S & RF & $\begin{array}{l}\text { fMRI - working } \\
\text { memory/sMRI }\end{array}$ & $\begin{array}{l}\text { Bootstrapped } \\
\text { validation }\end{array}$ & 137 adolescents & - & $\begin{array}{l}\text { Moderate/heavy alcohol } \\
\text { use versus. nonusers }\end{array}$ & $74 \% \mathrm{PA}$ \\
\hline $\begin{array}{l}\text { Steele et al., } \\
2017\end{array}$ & S & SVM & VBM & LOOCV & 143 offenders $21 \mathrm{HC}$ & & $\begin{array}{l}\text { High/low psychopathic } \\
\text { traits versus. HC }\end{array}$ & $69-82 \% \mathrm{PA}$ \\
\hline $\begin{array}{l}\text { Tang et al., } \\
2013 a\end{array}$ & S & SVM & rs-FNC & LOOCV & 32 ASPD $35 \mathrm{HC}$ & - & ASPD versus. $\mathrm{HC}$ & $86 \%$ PA \\
\hline $\begin{array}{l}\text { Tang et al., } \\
2013 b\end{array}$ & S & SVM & Regional homogeneity & LOOCV & $\begin{array}{l}32 \mathrm{ASPD} \\
34 \mathrm{HC}\end{array}$ & - & ASPD versus $\mathrm{HC}$ & $70 \% \mathrm{PA}$ \\
\hline $\begin{array}{l}\text { Wang et al., } \\
2018\end{array}$ & U & $\begin{array}{l}\text { Conv3d } \\
\text { deep learn- } \\
\text { ing }\end{array}$ & sMRI & 4-fold CV & $\begin{array}{l}61 \text { smokers } \\
66 \text { nonsmokers }\end{array}$ & - & $\begin{array}{l}\text { Smokers versus non- } \\
\text { smokers }\end{array}$ & $80.6-93.5 \%$ PA \\
\hline $\begin{array}{l}\text { Wei et al., } \\
2021\end{array}$ & S & $\begin{array}{l}\text { LASSO } \\
\text { regression }\end{array}$ & rs-FNC & LOOCV & $\begin{array}{l}24 \mathrm{CD} \\
24 \mathrm{HC}\end{array}$ & - & Empathy scores & $\begin{array}{l}\text { Model explained } 29.16 \% \text { of } \\
\text { the variance in empathy } \\
\text { scores. }\end{array}$ \\
\hline $\begin{array}{l}\text { Wetherill et al., } \\
2018\end{array}$ & S & SVM & rs-FNC & 10 -fold CV & 108 NUD 108 HC & - & NUD versus. control & $88.1 \%$ PA \\
\hline Yu et al., 2011 & S & SVM & VBM & LOOCV & $\begin{array}{l}16 \text { smokers } \\
16 \mathrm{HC}\end{array}$ & - & Smokers versus $\mathrm{HC}$ & $81.25 \%$ PA \\
\hline $\begin{array}{l}\text { Zhang et al., } \\
2019\end{array}$ & S & SVM & 3D sMRI & LOOCV & 60 Conduct Dis. $60 \mathrm{HC}$ & - & $\begin{array}{l}\text { Conduct Dis. versus. } \\
\text { control }\end{array}$ & $83 \%$ PA \\
\hline $\begin{array}{l}\text { Zhang et al., } \\
2018\end{array}$ & S & $\begin{array}{l}\text { SVM, LR, } \\
\text { RF }\end{array}$ & VBM & 5-fold CV & 60 Conduct Dis. $60 \mathrm{HC}$ & - & $\begin{array}{l}\text { Conduct Dis. versus. } \\
\text { control }\end{array}$ & $77.9 \%-80.4 \%$ PA \\
\hline $\begin{array}{l}\text { Zhang et al., } \\
2016\end{array}$ & S & SVM & rs-FNC & LOOCV & $\begin{array}{l}100 \mathrm{CD} \\
100 \mathrm{HC}\end{array}$ & - & $C D$ versus $H C$ & $72 \% \mathrm{PA}$ \\
\hline $\begin{array}{l}\text { Zhang et al., } \\
2011\end{array}$ & S & SVM & rs-fMRI & LOOCV & $12 \mathrm{HD} 13 \mathrm{HC}$ & - & HD versus. control & $65 \% \mathrm{PA}$ \\
\hline $\begin{array}{l}\text { Zhao et al., } \\
2020\end{array}$ & S & SVM & DTI & 10 -fold CV & $\begin{array}{l}70 \text { smokers } 70 \text { non- } \\
\text { smokers }\end{array}$ & - & $\begin{array}{l}\text { Smokers versus. } \\
\text { nonsmokers }\end{array}$ & $88.6 \%$ PA \\
\hline $\begin{array}{l}\text { Zhu et al., } \\
2018\end{array}$ & S & $\mathrm{RF}$ & $\begin{array}{l}\text { Within-/between- } \\
\text { network rs-FNC }\end{array}$ & $\begin{array}{l}\text { Bootstrapped } \\
\text { validation }\end{array}$ & $\begin{array}{l}46 \mathrm{AUD} \\
46 \mathrm{HC}\end{array}$ & - & AUD versus $\mathrm{HC}$ & $\begin{array}{l}\text { Within-network FNC: } 87 \% \text { PA } \\
\text { Between-network FNC: } \\
67.4 \% \text { PA }\end{array}$ \\
\hline \multicolumn{9}{|l|}{ Prognosis/Course } \\
\hline $\begin{array}{l}\text { Bertocci et al., } \\
2017\end{array}$ & S & $\begin{array}{l}\text { LASSO } \\
\text { regression }\end{array}$ & fMRI - reward and CT & 10 -fold CV & 73 youth & - & $\begin{array}{l}\text { 2-year future substance } \\
\text { use }\end{array}$ & $83.6 \% \mathrm{PA}$ \\
\hline $\begin{array}{l}\text { Clark et al., } \\
2014\end{array}$ & S & Multiple & $\begin{array}{l}\text { Selective attention } \\
\text { fMRI }\end{array}$ & 10 -fold CV & 45 SUD & - & Relapse versus no relapse & $77.8-89.9 \%$ PA \\
\hline
\end{tabular}




\begin{tabular}{|c|c|c|c|c|c|c|c|c|}
\hline $\begin{array}{l}\text { Kiehl et al., } \\
2018\end{array}$ & $\mathrm{~S}$ & $\begin{array}{l}\text { Cox regres- } \\
\text { sion }\end{array}$ & sMRI & 10 -fold CV & 93 offenders & - & Reoffending & not reported \\
\hline $\begin{array}{l}\text { Gowin et al., } \\
2019\end{array}$ & $\mathrm{~S}$ & RF & fMRI - reward related & IS & 63 MUD & 29 CUD & $\begin{array}{l}\text { Relapse versus. absti- } \\
\text { nence }\end{array}$ & $\begin{array}{l}\text { Training: 65\% PA Testing: } \\
\text { NS }\end{array}$ \\
\hline $\begin{array}{l}\text { Gowin et al., } \\
2015\end{array}$ & $\mathrm{~s}$ & RF & fMRI - reward related & $\begin{array}{l}\text { Bootstrapped } \\
\text { validation }\end{array}$ & 69 MUD & - & $\begin{array}{l}\text { Relapse versus. absti- } \\
\text { nence }\end{array}$ & $72-75 \%$ PA \\
\hline $\begin{array}{l}\text { Sekutowicz } \\
\text { et al., } 2019\end{array}$ & $\mathrm{~S}$ & SVM & $\begin{array}{l}\text { Pavlonian-to-instru- } \\
\text { mental fMRI }\end{array}$ & LOOCV & 52 detoxified $A D$ & - & $\begin{array}{l}\text { 12-month relapse versus. } \\
\text { abstinence }\end{array}$ & $71.2 \% \mathrm{PA}$ \\
\hline Seo et al. 2015 & $\mathrm{~S}$ & $\begin{array}{l}\text { SVM, NB, } \\
\text { VQ }\end{array}$ & $\begin{array}{l}\text { VBM/fMRI - cue reac- } \\
\text { tivity }\end{array}$ & LOOCV & $46 \mathrm{AD}$ & - & $\begin{array}{l}\text { 3-month relapse versus } \\
\text { abstinence }\end{array}$ & $73-79 \%$ PA \\
\hline $\begin{array}{l}\text { Spechler et al., } \\
2019\end{array}$ & $\mathrm{~S}$ & $\begin{array}{l}\text { Logistic } \\
\text { regression }\end{array}$ & $\begin{array}{l}\text { Task-realted fMRI/ } \\
\text { sMRI }\end{array}$ & 10 -fold CV & 158114 year olds & - & Cannabis/alcohol use & $A \cup C=0.65-0.82$ \\
\hline $\begin{array}{l}\text { Steele et al. } \\
2015\end{array}$ & $\mathrm{~S}$ & SVM & fMRI/EEG - Go/No-Go & LOOCV & 45 offenders & - & Reoffending & $83 \% \mathrm{PA}$ \\
\hline $\begin{array}{l}\text { Whelan et al., } \\
2014\end{array}$ & $\mathrm{~S}$ & $\begin{array}{l}\text { LG, } \\
\text { Elasticnet }\end{array}$ & $\begin{array}{l}\text { Multimodal fMRI/ } \\
\text { genetic/personality/ } \\
\text { environmental }\end{array}$ & 10 -fold CV & 692 adolescents & - & Binge drinking & $93-95 \%$ PA \\
\hline \multicolumn{9}{|c|}{ Subtyping/Heterogeneity } \\
\hline $\begin{array}{l}\text { Fede et al., } \\
2019\end{array}$ & $\mathrm{~s}$ & $\begin{array}{l}\text { RF regres- } \\
\text { sion }\end{array}$ & Multimodal rs-FNC & 10-fold CV and IS & $\begin{array}{l}59 \text { with moderate/ } \\
\text { heavy alcohol use }\end{array}$ & $\begin{array}{l}24 \text { with moderate/ } \\
\text { heavy alcohol use }\end{array}$ & Alcohol use severity & $\begin{array}{l}\text { Training: } \mathrm{R}^{2}: 98.7 \text { Testing: } \\
\mathrm{R}^{2}: 33.2\end{array}$ \\
\hline $\begin{array}{l}\text { Joseph et al., } \\
2019\end{array}$ & $\mathrm{~s}$ & ALM & rs-FNC & 10-fold CV & 83 CUD & - & Years of cocaine use & $R^{2}=8-20 \%$ \\
\hline $\begin{array}{l}\text { Steele et al., } \\
2017\end{array}$ & $\mathrm{~S}$ & SVM & VBM & LOOCV & 143 offenders $21 \mathrm{HC}$ & - & High/Low PCL-YV & $69.23 \% \mathrm{PA}$ \\
\hline $\begin{array}{l}\text { Wetherill et al., } \\
2019\end{array}$ & $\mathrm{~S}$ & SVM & rs-FNC & 10 -fold CV & 108 NUD 108 HC & - & NUD versus. $\mathrm{HC}$ & $88.1 \%$ PA \\
\hline $\begin{array}{l}\text { Zilverstand } \\
\text { et al. } 2018\end{array}$ & $u$ & $\begin{array}{l}\text { K-centroid } \\
\text { clustering }\end{array}$ & rs-FNC & LOOCV & 42 CUD $32 \mathrm{HC}$ & - & Within CUD heterogeneity & $\begin{array}{l}\text { CUD subtypes classified via } \\
\text { neurocognitive profile }\end{array}$ \\
\hline \multicolumn{9}{|c|}{ Treatment/Rehabilitation } \\
\hline $\begin{array}{l}\text { Luo et al., } \\
2014\end{array}$ & $\mathrm{~s}$ & SVM & rs-PET & 10 -fold CV & 25 CUD & - & $\begin{array}{l}\text { Treatment responders } \\
\text { versus Nonresponders }\end{array}$ & $82 \% \mathrm{PA}$ \\
\hline $\begin{array}{l}\text { MacNiven } \\
\text { et al., } 2018\end{array}$ & $S$ & $\begin{array}{l}\text { Logistic } \\
\text { regression }\end{array}$ & fMRI - Cue reactivity & LOOCV & $\begin{array}{l}36 \text { SUD } \\
40 \mathrm{HC}\end{array}$ & - & Relapse versus abstain & $75.8 \% \mathrm{PA}$ \\
\hline $\begin{array}{l}\text { Steele et al., } \\
2018\end{array}$ & $\mathrm{~S}$ & SVM & Task-FNC Go/No-Go & 10 -fold & 139 offenders & - & $\begin{array}{l}\text { Treatment completion } \\
\text { versus dropout }\end{array}$ & $80.6 \%$ PA \\
\hline Yip et al., 2019 & $\mathrm{~S}$ & CPM & rs-FNC & $\begin{array}{l}\text { LOOCV and } \\
\text { independent Sample }\end{array}$ & 53 CUD & 45 CUD & $\begin{array}{l}\text { Abstinence during treat- } \\
\text { ment }\end{array}$ & Testing: $64-71 \%$ PA \\
\hline
\end{tabular}

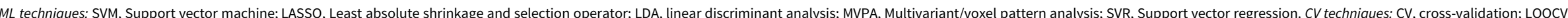

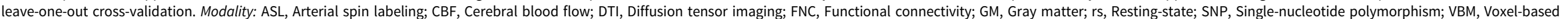

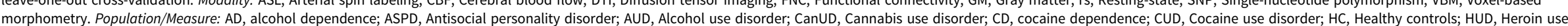
disorder; MUD, Methamphetamine use disorder; NUD, Nicotine use disorder; PCL-R, Psychopathy Checklist - Revised (Hare, 1991); PCL-YV = Psychopathy Checklist Youth Version (Forth et al., 2003); SUD, Substance use disorder. 
Table 2. Some of the major open-access ML tools that include GUI interfaces (or have lower coding requirements)

\begin{tabular}{|c|c|c|}
\hline \multicolumn{3}{|l|}{ Tools with GUI interfaces } \\
\hline PRoNTo & Schrouff et al. (2013) & $\begin{array}{l}\text { MATLAB toolbox with GUI interface (and MATLAB batch script creation capabilities), for a wide range of } \\
\text { categorical and continuous ML methods. }\end{array}$ \\
\hline MALINI & Lanka et al. (2020) & A MATLAB toolbox for aiding clinical diagnostics using resting-state fMRI data. \\
\hline GraphVar & Waller et al. (2018) & A user-friendly toolbox for comprehensive graph analyses of functional brain connectivity. \\
\hline MVPANI & Peng et al. (2020) & Multimodal, multivariate MVPA with a friendly graphical interface. \\
\hline WekaDeepLearning4J & Lang et al. (2019) & A deep learning module for Weka that supports a variety of hierarchical and network-based models. \\
\hline \multicolumn{3}{|c|}{ Tools with lower coding requirements } \\
\hline SHOGUN & $\begin{array}{l}\text { Sonnenburg et al. } \\
\text { (2010) }\end{array}$ & $\begin{array}{l}\text { Multi-platform open-source machine learning library that offers a wide range of efficient and unified } \\
\text { machine learning methods. Large cookbook of codes are available. }\end{array}$ \\
\hline CosmoMVPA & Oosterhof et al. (2016) & A multivariate, multimodal (fMRI volumetric, fMRI surface-based, and MEEG) MATLAB toolbox. \\
\hline
\end{tabular}

of this nature, toward a more detailed understanding of the mechanisms underlying externalizing pathology.

\subsection{The challenges ahead}

\subsubsection{Small sample sizes}

A common limitation of most studies to date is their reliance on small sample sizes, which reduces precision (or, in the parlance of machine learning, increases the likelihood of overfitting). Fortunately, with an increase in multisite and consortium efforts, large comprehensive datasets of this nature are becoming increasingly available. Several large studies have recently been reported (Espinoza et al., 2019), and consortium efforts are quickly organizing (e.g., ENIGMA; Thompson, 2019). These are perfect for the application of machine learning tools, and offer the prospects of sufficiently sophisticated analyses, within a reasonable time frame, to make the fine-grained distinctions necessary to answer critical questions pertaining to comorbidity/heterogeneity. Additional use of machine learning tools on these large datasets may increase the ability to predict prognosis and course of externalizing disorders by taking into account subject-specific factors (see (Walter et al., 2019) for elaboration), to afford early detection/identification of individuals with poor prognosis, or to afford new avenues for patient stratification and early intervention. Issues regarding sample size will continue to be a concern, however; particularly as deep-learning models gain additional traction in translational applications (for review, see Vieira et al., 2017), as these models may require sample sizes orders of magnitude larger than traditional ML pipelines.

\subsubsection{Expertise is scarce}

Personality theory, psychiatry, neuroscience, and machine learning require quite diverse forms of expertise, which puts necessary limits on full integration of these disciplines. Thus, to large extent, the initiation of sophisticated machine learning architecture will require collaborative efforts that cut across disciplinary lines. In addition, and fortunately, recent advances in both software and hardware are making computational modelling and machine learning more accessible. For instance, recent multidisciplinary initiatives have sought to develop more user-friendly versions of computational (e.g., hBayesDM in R), and machine learning (e.g., EasyML; Hendricks \& Ahn, 2017) software that can allow those familiar with theoretical, if not technical, requirements of these methods to develop sophisticated models (see Table 2 for a list of available packages). These advances will no doubt continue to increase accessibility as time goes on (see also (Durstewitz et al., 2019) for additional considerations of potential solutions.

\subsubsection{The black box}

A common push/pull in analytic circles is the debate over datadriven versus theory-driven models. In this regard, data-driven methods are often criticized for their "black box" nature (Davatzikos, 2019), and for their disconnect from clinical and theoretical relevance. However, as Huys et al. (2016) point out, data-driven and theory-driven computational methods can complement each other, toward a deeper understanding of disorder characteristics. Common usage today is for datadriven methods to be employed to initially reduce the dimensionality of complex, multimodal datasets, and to allow for the construction of more digestible theoretical models (Allen et al., 2011). As the field is in its early days, this approach may offer the most efficient and productive ability to scour the massive amount of data that translational neuroimaging can provide. However, as the field matures, the opposite order may become increasingly beneficial: that is, theory-driven dimensionality reduction, followed by more powerful datadriven approaches that search through the theoretically relevant variables with the most sophisticated and efficient pattern analysis techniques (e.g., (Maia, Huys, \& Frank, 2017)). This can retain a tight clinical/theoretical focus capable of supporting experimentally driven univariate analyses, while also achieving the analytical brawn that machine learning techniques can offer. 


\subsubsection{Differential reliability of neurobiological predictors}

Finally, while the paper's primary intent is to highlight the strengths of using data-driven techniques to interrogate complex relationships between antisociality and SUD, we conclude by reminding that the validity and reliability of a predictive model can only be as high as the validity and reliability of the predictors used toward model prediction (see Fröhner et al., 2019). In this regard, the greatest strengths of these data-driven models may also be their greatest weakness: they will essentially move mountains to identify underlying patterns in the data - valid, reliable, or otherwise. Thus, as the use of machine learning models becomes more prevalent, researchers will need to be increasingly vigilant about their choice of predictor constructs, and of those predictors' inherent reliability/validity. In this vein, it may be prudent to note that functional MRI, in particular, has been criticized recently for potentially low internal consistency (Infantolino et al., 2018) and test-retest reliability (Elliott et al., 2020). Though this issue is hardly unique to fMRI, or even neuroimaging (e.g., Anvari \& Lakens, 2018; Świątkowski \& Dompnier, 2017), and may indeed be somewhat overblown (Pannunzi et al., 2017), it does underline the need for best practices in the field: always carefully consider your model parameters, always aim to demonstrate clinical utility, and always make use of validation techniques to maximize the potential generalizability of study findings.

Acknowledgements. We would like to acknowledge and thank the work of Mr. Ben Wasserott, as well as of Ms. Roberta Chavez and the entire Program Evaluation Services (PES) at the Center on Alcoholism, Substance Abuse, and Addictions (CASAA) at the University of New Mexico, who greatly facilitated participant recruitment and managed the majority of clinical assessments. We would also like to acknowledge Ms. Isabelle Simard, who facilitated data preprocessing and data management.

Financial Support. This work was supported by a Natural Science and Research Foundation of Canada (NSERC) Discovery Grant (RGPIN/0069642020) awarded to Dr. Shane. The NSERC support is greatly appreciated; NSERC did not have any role in the design and conduct of the study, in the collection, management, analysis, and interpretation of the data, or in the preparation, review, or approval of the manuscript.

Conflicts of Interest. None.

\section{References}

Abram, S. V., Wisner, K. M., Grazioplene, R. G., Krueger, R. F., MacDonald, A. W., \& DeYoung, C. G. (2015). Functional coherence of insula networks is associated with externalizing behavior. Journal of Abnormal Psychology, 124, 1079-1091. http://doi.org/10.1037/abn0000078.

Allen, E. A., Erhardt, E. B., Damaraju, E., Gruner, W., Segall, J. M., Silva, R. F., \& Kalyanam, R. (2011). A baseline for the multivariate comparison of resting-state networks. Frontiers in Systems Neuroscience, 5, 1-23. http:// doi.org/10.3389/fnsys.2011.00002.

Alpaydin, E. (2014). Introduction to machine learning (3rd ed.). Cambridge, MA: MIT Press.

Amen, D., Darmal, B., Raji, C., Bao, W.Jorandby, L., Meysami, S., \& Raghavendra, C. (2017). Discriminative properties of hippocampal hypoperfusion in marijuana users compared to healthy controls: Implications for marijuana administration in Alzheimer's dementia. Journal of Alzheimer's Disease, 56, 261-273. https://doi.org/ 10.3233/JAD-160833

Anderson, A., Douglas, P.K., Kerr, W.T., Haynes, V.S., Yuille, A.L., Xie, J., \& Cohen, M.S. (2014). Non-negative matrix factorization of multimodal MRI, fMRI and phenotypic data reveals differential changes in default mode subnetworks in ADHD. NeuroImage, 102, 207-219. http://doi.org/10.1016/j. neuroimage.2013.12.015.
Anvari, F., \& Lakens, D. (2018). The replicability crisis and public trust in psychological science. Comprehensive Results in Social Psychology, 3, 266286. http://doi.org/10.1080/23743603.2019.1684822.

Baskin-Sommers, A. R., Curtin, J. J., \& Newman, J. P. (2015). Altering the cognitive-affective dysfunctions of psychopathic and externalizing offender subtypes with cognitive remediation. Clinical Psychological Science, 3, 45-57. http://doi.org/10.1177/2167702614560744.

Beckmann, C. F., DeLuca, M., Devlin, J. T., \& Smith, S. M. (2005). Investigations into resting-state connectivity using independent component analysis. Philosophical Transactions of the Royal Society B: Biological Sciences, 360, 1001-1013. http://doi.org/10.1098/rstb.2005.1634.

Bertocci, M., Bebko, G., Versace, A., Iyengar, S., Bonar, L., Forbes, E., .. Findling, R. L. (2017). Reward-related neural activity and structure predict future substance use in dysregulated youth. Psychological Medicine, 47, 13571369. http://doi.org/10.1017/S0033291716003147.

Bi, X. A., Wang, Y., Shu, Q., Sun, Q., \& Xu, Q. (2018). Classification of autism spectrum disorder using random support vector machine cluster. Frontiers in Genetics, 9-18. http://doi.org/10.3389/fgene.2018.00018.

Brazil, I. A., van Dongen, J. D. M., Maes, J. H. R., Mars, R. B., \& BaskinSommers, A. R. (2018). Classification and treatment of antisocial individuals: From behavior to biocognition. Neuroscience \& Biobehavioral Reviews, 91, 259-277. http://doi.org/10.1016/J.NEUBIOREV.2016.10.010.

Brislin, S.J., \& Patrick, C.J. (2019). Callousness and affective face processing: Clarifying the neural basis of behavioral-recognition deficits through the use of brain event-related potentials. Clinical Psychological Science, 7, 1389-1402. http://doi.org/10.1177/2167702619856342.

Bzdok, D., \& Ioannidis, J. P. (2019). Exploration, inference, and prediction in neuroscience and biomedicine. Trends in Neurosciences, 42, 251-262.

Bzdok, D., \& Meyer-Lindenberg, A. (2018). Machine learning for precision psychiatry: Opportunities and challenges. Biological Psychiatry: Cognitive Neuroscience and Neuroimaging, 3, 223-230. http://doi.org/10.1016/j.bpsc. 2017.11.007.

Bzdok, D., \& Meyer-Lindenberg, A. (2019). Exploration, inference, and prediction in neuroscience and biomedicine. Trends in Neurosciences, 42, 251262. http://doi.org/10.1016/j.tins.2019.02.001.

Bzdok, D., Nichols, T. E., \& Smith, S. M. (2019). Towards algorithmic analytics for large-scale datasets. Nature Machine Intelligence, 1, 296-306. http:// doi.org/10.1038/s42256-019-0069-5.

Calhoun, V. D., Kiehl, K. A., \& Pearlson, G. D. (2008). Modulation of temporally coherent brain networks estimated using ICA at rest and during cognitive tasks. Human Brain Mapping, 29, 828-838. http://doi.org/10.1002/ hbm.20581.

Calhoun, V. D., Liu, J., \& Adal, T. (2009). A review of group ICA for fMRI data and ICA for joint inference of imaging, genetic, and ERP data. Neuroimage, 45, S163-S172. http://doi.org/10.1016/j.neuroimage.2008.10.057.

Caspi, A., Houts, R. M., Belsky, D. W., Goldman-Mellor, S. J., Harrington, H., Israel, S., Meier, M.H., Ramrakha, S., Shalev, I., Poulton, R., \& Moffitt, T. E. (2014). The $\mathrm{p}$ factor: One general psychopathology factor in the structure of psychiatric disorders? Clinical Psychological Science, 2, 119-137. http://doi.org/10.1177/2167702613497473.

Cearns, M., Hahn, T., Clark, S., \& Baune, B. T. (2019). Machine learning probability calibration for high-risk clinical decision-making. SAGE Publications UK

Cha, J., Greenberg, T., Song, I., Blair Simpson, H., Posner, J., \& MujicaParodi, L. R. (2016). Abnormal hippocampal structure and function in clinical anxiety and comorbid depression. Hippocampus, 26, 545-553. http://doi. org/10.1002/hipo.22566

Chen, C., Zhou, J., Liu, C., Witt, K., Zhang, Y., Jing, B., . . L Li, L. (2015). Regional homogeneity of resting-state brain abnormalities in violent juvenile offenders: A biomarker of brain immaturity? The Journal of Neuropsychiatry and Clinical Neurosciences, 27, 27-32. http://doi.org/10.1176/appi. neuropsych.13030044

Chung, M., Martins, B., Privratsky, A., James, G., Kilts, C., \& Bush, K. (2018). Individual differences in rate of acquiring stable neural representations of tasks in fMRI. PloS One, 13, 1-17. https://doi.org/10.1371/journal.pone. 0207352

Clark, V., Beatty, G., Anderson, R., Kodituwakku, P., Phillips, J., Lane, T., \& Calhoun, V. (2014). Reduced fMRI activity predicts relapse in patients 
recovering from stimulant dependence. Human Brain Mapping, 35, 414-428. http://doi.org/10.1002/hbm.22184.

Cohn, M. D., Pape, L. E., Schmaal, L., van den Brink, W., van Wingen, G., Vermeiren, R. R. J. M., \& Popma, A. (2015). Differential relations between juvenile psychopathic traits and resting state network connectivity. Human Brain Mapping, 36, 2396-2405. http://doi.org/10.1002/hbm.22779.

Conway, C. C., Forbes, M. K., Forbush, K. T., Fried, E. I., Hallquist, M. N., Kotov, R., \& Eaton, N. R. (2019). A hierarchical taxonomy of psychopathology can transform mental health research. Perspectives on Psychological Science, 14, 419-436. http://doi.org/10.1177/1745691618810696.

Cope, L., Ermer, E., Gaudet, L., Steele,V., Eckhardt, A., Arbabshirani, M.,

Kiehl, K. (2014). Abnormal brainstructure in youth who commit homicide. NeuroImage: Clinical, 4, 800-807. https://doi.org/10.1016/j.nicl. 2014.05.

Costafreda, S. G., Chu, C., Ashburner, J., \& Fu, C. H. Y. (2009). Prognostic and diagnostic potential of the structural neuroanatomy of depression. PloS One, 4, 1-5. http://doi.org/10.1371/journal.pone.0006353.

Cuthbert, B. N., \& Insel, T. R. (2013). Toward the future of psychiatric diagnosis: The seven pillars of RDoC. BMC Medicine, 11, 1-8. http://doi.org/10. 1186/1741-7015-11-126.

Davatzikos, C. (2019). Machine learning in neuroimaging: Progress and challenges. NeuroImage, 197, 652-656. http://doi.org/10.1016/j.neuroimage. 2018.10.003.

Denomme, W. J., \& Shane, M. S. (2020). History of withdrawal modulates drug-and food-cue reactivity in cocaine dependent participants. Drug and Alcohol Dependence, 208, 107815. http://doi.org/10.1016/j.drugalcdep. 2019.107815.

Denomme, W. J., Simard, I., \& Shane, M. S. (2018). Neuroimaging metrics of drug and food processing in cocaine-dependence, as a function of psychopathic traits and substance use severity. Frontiers in Human Neuroscience, 12, 350. https://doi.org/10.3389/fnhum.2018.00350.

Ding, X., Yang, Y., Stein, E., \& Ross, T. (2015). Multivariate classification of smokers and nonsmokers using SVM-RFE on structural MRI images. Human Brain Mapping, 36, 4869-4879. http://doi.org/10.1002/hbm.22956.

Ding, X., Yang, Y., Stein, E., \& Ross, T. (2017). Combining multiple restingstate fMRI features during classification: Optimized frameworks and their application to nicotine addiction. Frontiers in Human Neuroscience, 11, 1-14. http://doi.org/10.3389/fnhum.2017.00362.

Drysdale, A. T., Grosenick, L., Downar, J., Dunlop, K., Mansouri, F., Meng, Y., \& Etkin, A. (2017). Resting-state connectivity biomarkers define neurophysiological subtypes of depression. Nature Medicine, 23, 28-38. http://doi. org/10.1038/nm.4246.

Du, Y., Pearlson, G. D., Liu, J., Sui, J., Yu, Q., He, H., \& Calhoun, V. D. (2015). A group ICA based framework for evaluating resting fMRI markers when disease categories are unclear: application to schizophrenia, bipolar, and schizoaffective disorders. Neuroimage, 122, 272-280. http://doi.org/10. 1016/j.neuroimage.2015.07.054.

Durstewitz, D., Koppe, G., \& Meyer-Lindenberg, A. (2019). Deep neural networks in psychiatry. Molecular Psychiatry, 24, 1583-1598. http://doi.org/10. 1038/s41380-019-0365-9.

Dwyer, D. B., Falkai, P., \& Koutsouleris, N. (2018). Machine learning approaches for clinical psychology and psychiatry. Annual Review of Clinical Psychology, 14, 91-118. http://doi.org/10.1146/annurev-clinpsy032816-045037.

Elliott, M.L., Knodt, A.R., Ireland, D., Morris, M.L., Poulton, R., Ramrakha, S., \& Hariri, A.R. (2020). What is the test-retest reliability of common taskfunctional MRI measures? New empirical evidence and a meta-analysis. Psychological Science, 31, 792-806. http://doi.org/10.1177/09567976 20916786.

Elton, A., Young, J., Smitherman, S., Gross, R., Mletzko, T., \& Kilts, C. (2014). Neural network activation during a stop-signal task discriminates cocaine-dependent from non-drug-abusing men. Addiction Biology, 19, 427-438. http://doi.org/10.1111/adb.12011.

Espinoza, F. A., Anderson, N. E., Vergara, V. M., Harenski, C. L., Decety, J., Rachakonda, S., \& Harenski, K. (2019). Resting-state fMRI dynamic functional network connectivity and associations with psychopathy traits. NeuroImage: Clinical, 24, 1-9. http://doi.org/10.1016/j.nicl.2019. 101970.
Fanti, K. A., \& Kimonis, E. (2017). Heterogeneity in externalizing problems at age 3: Association with age 15 biological and environmental outcomes. Developmental Psychology, 53, 1230-1241. http://doi.org/10.1037/ dev0000317.

Fede, S., Grodin, E., Dean, S., Diazgranados, N., \& Momenan, R. (2019). Resting state connectivity best predicts alcohol use severity in moderate to heavy alcohol users. NeuroImage: Clinical, 22, 1-10. http://doi.org/10. 1016/j.nicl.2019.101782.

Fink, B. C., Steele, V. R., Maurer, M. J., Fede, S. J., Calhoun, V. D., \& Kiehl, K. A. (2016). Brain potentials predict substance abuse treatment completion in a prison sample. Brain and Behavior, 6, 1-14. http://doi.org/10.1002/ brb3.501.

Forth AE, Kosson DS, Hare RD. The Psychopathy Checklist: Youth Version. Toronto, Ontario, Canada: Multi-Health Systems; 2003.

Frank, E., Hall, M.A., \& Witten, I.H. (2016). The WEKA Workbench. Online Appendix for Data Mining: Practical Machine Learning Tools and Techniques, Morgan Kaufmann, 4th Ed.

Friston, K. J., Redish, A. D., \& Gordon, J. A. (2017). Computational nosology and precision psychiatry. Computational Psychiatry, 1, 2-23. http://doi.org/ 10.1162/CPSY_a_00001.

Fröhner, J. H., Teckentrup, V., Smolka, M. N., \& Kroemer, N. B. (2019). Addressing the reliability fallacy in fMRI: Similar group effects may arise from unreliable individual effects. NeuroImage, 195, 174-189. http://doi. org/10.1016/j.neuroimage.2019.03.053.

Goldberg, L. R. (1990). An alternative" description of personality": The big-five factor structure. Journal of Personality and Social Psychology, 59, 1216-1229. http://doi.org/10.1037/0022-3514.59.6.1216.

Gowin, J., Ball, T., Wittmann, M., Tapert, S., \& Paulus, M. (2015). Individualized relapse prediction: Personality measures and striatal and insular activity during reward-processing robustly predict relapse. Drug and Alcohol Dependence, 152, 93-101. http://doi.org/10.1016/j.drugalcdep. 2015.04.018.

Gowin, J., Manza, P., Ramchandani, V., \& Volkow, N. (2020). Neuropsychosocial markers of binge drinking in young adults. Molecular Psychiatry. http://doi.org/10.1038/s41380-020-0771-z.

Gowin, J. L., Ernst, M., Ball, T., May, A. C., Sloan, M. E., Tapert, S. F., \& Paulus, M. P. (2019). Using neuroimaging to predict relapse in stimulant dependence: A comparison of linear and machine learning models. NeuroImage: Clinical, 21, 1-7. http://doi.org/10.1016/J.NICL.2019.101676.

Grotegerd, D., Redlich, R., Almeida, J.R.C., Riemenschneider, M., Kugel, H., Arolt, V., \& Dannlowski, U. (2014). MANIA - a pattern classification toolbox for neuroimaging data. Neuroinformatics, 12, 471-486. http://doi.org/10. 1007/s12021-014-9223-8.

Guggenmos, M., Scheel, M., Sekutowicz, M., Garbusow, M., Sebold, M., Sommer, C., \& Schmack, K. (2018). Decoding diagnosis and lifetime consumption in alcohol dependence from grey-matter pattern information. Acta Psychiatrica Scandinavica, 137, 252-262. http://doi.org/10.1111/acps.12848.

Guggenmos, M., Schmack, K., Veer, I., Lett, T., Sekutowicz, M., Sebold, M., \& Sterzer, P. (2020). A multimodal neuroimaging classifier for alcohol dependence. Scientific Reports, 10, 1-12. http://doi.org/10.1038/s41598019-56923-9.

Hamilton, J. P., Chen, M. C., Waugh, C. E., Joormann, J., \& Gotlib, I. H. (2014). Distinctive and common neural underpinnings of major depression, social anxiety, and their comorbidity. Social Cognitive and Affective Neuroscience, 10, 552-560. http://doi.org/10.1093/scan/nsu084.

Hare, R. D. (1991). Manual for the psychopathy checklist-revised. Toronto, Canada: Multi-Health Systems.

Hendricks, P., \& Ahn, W.-Y. (2017). Easyml: Easily Build And Evaluate Machine Learning Models. BioRxiv. http://doi.org/10.1101/137240.

Higgins, S.T., \& Budney, A.J. (1993). Treatment of cocaine dependence through the principles of behavior analysis and behavioral pharmacology. NIDA Research Monograph, 137, 97-121. http://doi.org/10.1037.

Hilbert, K., Lueken, U., Muehlhan, M., \& Beesdo-Baum, K. (2017). Separating generalized anxiety disorder from major depression using clinical, hormonal, and structural MRI data: A multimodal machine learning study. Brain and Behavior, 7, 1-11. http://doi.org/10.1002/brb3.633.

Hopwood, C. J., Zimmermann, J., Pincus, A. L., \& Krueger, R. F. (2015). Connecting personality structure and dynamics: Towards a more 
evidence-based and clinically useful diagnostic scheme. Journal of Personality Disorders, 29, 431-448. http://doi.org/10.1521/pedi.2015.29.4. 431.

Huys, Q. J. M., Maia, T. V, \& Frank, M. J. (2016). Computational psychiatry as a bridge from neuroscience to clinical applications. Nature Neuroscience, 19, 404-413. http://doi.org/10.1038/nn.4238.

Hyatt, C. S., Owens, M. M., Gray, J. C., Carter, N. T., MacKillop, J., Sweet, L. H., \& Miller, J. D. (2019). Personality traits share overlapping neuroanatomical correlates with internalizing and externalizing psychopathology. Journal of Abnormal Psychology, 128, 1-11. http://doi.org/10.1037/ abn0000391.

Infantolino, Z. P., Luking, K. R., Sauder, C. L., Curtin, J. J., \& Hajcak, G. (2018). Robust is not necessarily reliable: From within-subjects fMRI contrasts to between-subjects comparisons. NeuroImage, 173, 146-152. http:// doi.org/10.1016/j.neuroimage.2018.02.024.

Insel, T., Cuthbert, B., Garvey, M., Heinssen, R., Pine, D. S., Quinn, K., \& Wang, P. (2010). Research domain criteria (RDoC): Toward a new classification framework for research on mental disorders. American Journal of Psychiatry, 167, 748-751. http://doi.org/10.1176/appi.ajp.2010. 09091379.

Janssen, R. J., Mourão-Miranda, J., \& Schnack, H. G. (2018). Making individual prognoses in psychiatry using neuroimaging and machine learning. Biological Psychiatry: Cognitive Neuroscience and Neuroimaging, 3, 798808. http://doi.org/10.1016/j.bpsc.2018.04.004.

Joseph, J., Vaughan, B., Camp, C., Baker, N., Sherman, B., Moran-Santa Maria, M., \& Brady, K. (2019). Oxytocin-induced changes in intrinsic network connectivity in cocaine use disorder: Modulation by gender, childhood trauma, and years of use. Frontiers in Psychiatry, 10, 1-14. http://doi.org/10. 3389/fpsyt.2019.00502.

Kamarajan, C., Ardekani, B., Pandey, A., Kinreich, S., Pandey, G., Chorlian, D., \& Porjesz, B. (2020). Random forest classification of alcohol use disorder using fMRI functional connectivity, neuropsychological functioning, and impulsivity measures. Brain Sciences, 10, 1-22. http://doi.org/10.3390/ brainsci10020115.

Kambeitz, J., Cabral, C., Sacchet, M. D., Gotlib, I. H., Zahn, R., Serpa, M. H., \& Koutsouleris, N. (2017). Detecting neuroimaging biomarkers for depression: A meta-analysis of multivariate pattern recognition studies. Biological Psychiatry, 82, 330-338. http://doi.org/10.1016/j.biopsych.2016.10.028.

Kiehl, K. A., Anderson, N. E., Aharoni, E., Maurer, J. M., Harenski, K. A., Rao, V., \& Decety, J. (2018). Age of gray matters: Neuroprediction of recidivism. Neuroimage: Clinical, 19, 813-823. http://doi.org/10.1016/j.nicl.2018. 05.036 .

Kircanski, K., White, L. K., Tseng, W.-L., Wiggins, J. L., Frank, H. R., Sequeira, S., \& Stringaris, A. (2018). A latent variable approach to differentiating neural mechanisms of irritability and anxiety in youth. JAMA Psychiatry, 75, 631-639. http://doi.org/10.1001/jamapsychiatry.2018.0468.

Koob, G. F., \& Volkow, N. D. (2010). Neurocircuitry of addiction. Neuropsychopharmacology, 35, 217-238. http://doi.org/10.1038/npp.2009. 110.

Kotov, R., Krueger, R. F., Watson, D., Achenbach, T. M., Althoff, R. R., Bagby, R. M., \& Zimmerman, M. (2017). The Hierarchical Taxonomy of Psychopathology (HiTOP): A dimensional alternative to traditional nosologies. Journal of Abnormal Psychology, 126, 454-477. http://doi.org/10.1037/ abn0000258.

Krueger, R. F., Hicks, B. M., Patrick, C. J., Carlson, S. R., Iacono, W. G., \& McGue, M. (2002). Etiologic connections among substance dependence, antisocial behavior, and personality: modeling the externalizing spectrum. Journal of Abnormal Psychology, 111, 411-424. http://doi.org/10.1037/ 0021-843X.111.3.411.

Krueger, R. F., Hopwood, C. J., Wright, A. G. C., \& Markon, K. E. (2014). DSM-5 and the path toward empirically based and clinically useful conceptualization of personality and psychopathology. Clinical Psychology: Science and Practice, 21, 245-261. http://doi.org/10.1111/cpsp.12073.

Krueger, R. F., Markon, K. E., Patrick, C. J., Benning, S. D., \& Kramer, M. D. (2007). Linking antisocial behavior, substance use, and personality: An integrative quantitative model of the adult externalizing spectrum. Journal of Abnormal Psychology, 116, 645-666. http://doi.org/10.1037/0021-843X. 116.4.645.
Lang, S., Bravo-Marquez, F., Beckham, C., Hall, M., \& Frank, E. (2019). WekaDeeplearning4j: A deep learning package for weka based on DeepLearning4j. Knowledge-Based Systems, 178, 48-50. http://doi.org/10. 1016/j.knosys.2019.04.013.

Lanka, P., Rangaprakash, D., Gotoor, S. S. R., Dretsch, M. N., Katz, J. S., Denney T. Jr, S., \& Deshpande, G. (2020). MALINI (Machine Learning in NeuroImaging): A MATLAB toolbox for aiding clinical diagnostics using resting-state fMRI data. Data in Brief, 29, 1-9. http://doi.org/10.1016/j.dib. 2020.105213.

Latzman, R.D., DeYoung, C.G. \& The HiTOP Neurobiological Foundations Workgroup. (2020). Using empirically-derived dimensional phenotypes to accelerate clinical neuroscience: The Hierarchical Taxonomy of Psychopathology (HiTOP) framework. Neuropsychopharmacology, 45, 1083-1085. http://doi.org/10.1038/s41386-020-0639-6.

Li, Y., Cui, Z., Liao, Q., Dong, H., Zhang, J., Shen, W., \& Zhou, W. (2019). Support vector machine-based multivariate pattern classification of methamphetamine dependence using arterial spin labeling. Addiction Biology, 24, 1254-1262. http://doi.org/10.1111/adb.12705.

Lichenstein, S. D., Scheinost, D., Potenza, M. N., Carroll, K. M., \& Yip, S. W. (2019). Dissociable neural substrates of opioid and cocaine use identified via connectome-based modelling. Molecular Psychiatry, online. http://doi.org/ 10.1038/s41380-019-0586-y.

Liu, F., Guo, W., Fouche, J., Wang, Y., Wang, W., Ding, J., \& Chen, H. (2015). Multivariate classification of social anxiety disorder using whole brain functional connectivity. Brain Structure and Function, 220, 101-115. http://doi. org/10.1007/s00429-013-0641-4.

Liu, S., Liu, S., Cai, W., Pujol, S., Kikinis, R., \& Feng, D. (2014). Early diagnosis of Alzheimer's disease with deep learning. Symposum at 2014 IEEE 11th International Symposium on Biomedical Imaging (ISBI), Beijing, China, 1015-1018. http://doi.org/10.1109/ISBI.2014.6868045.

Lottman, K. K., White, D. M., Kraguljac, N. V, Reid, M. A., Calhoun, V. D., Catao, F., \& Lahti, A. C. (2018). Four-way multimodal fusion of $7 \mathrm{~T}$ imaging data using an mCCA + jICA model in first-episode schizophrenia. Human Brain Mapping, 39, 1475-1488. http://doi.org/10.1002/hbm.23906.

Luo, J., Yang, R., Yang, W., Duan, C., Deng, Y., Zhang, J., \& Liu, J. (2020). Increased amplitude of low-frequency fluctuation in right angular gyrus and left superior occipital gyrus negatively correlated with heroin use. Frontiers in Psychiatry, 11, 1-8. http://doi.org/10.3389/fpsyt.2020.00492.

Luo, S., Martinez, D., Carpenter, K., Slifstein, M., \& Nunes, E. (2014). Multimodal predictive modeling of individual treatment outcome in cocaine dependence with combined neuroimaging and behavioral predictors. Drug and Alcohol Dependence, 143, 29-35. http://doi.org/10.1016/j.drugalcdep. 2014.04.030.

Mackey, S., Allgaier, N., Chaarani, B., Spechler, P., Orr, C., Bunn, J., \& Garavan, H. (2019). Mega-analysis of gray matter volume in substance dependence: General and substance-specific regional effects. The American Journal of Psychiatry, 176, 119-128. http://doi.org/10.1176/appi. ajp.2018.17040415.

MacNiven, K., ELS, J., Borg, N., Padula, C., Humphreys, K., \& Nutson, B. (2018). Association of neural responses to drug cues with subsequent relapse to stimulant use. JAMA Network Open, 1, 1-14. http://doi.org/10.1001/ jamanetworkopen.2018.6466.

Maia, T. V, Huys, Q. J. M., \& Frank, M. J. (2017). Theory-based computational psychiatry. Biological Psychiatry, 82, 382-384. http://doi.org/10.1016/j. biopsych.2017.07.016.

Mathotaarachchi, S., Pascoal, T. A., Shin, M., Benedet, A. L., Kang, M. S., Beaudry, T., \& Initiative, A. D. N. (2017). Identifying incipient dementia individuals using machine learning and amyloid imaging. Neurobiology of Aging, 59, 80-90. http://doi.org/10.1016/j.neurobiolaging.2017.06.027.

Meda, S. A., Narayanan, B., Liu, J., Perrone-Bizzozero, N. I., Stevens, M. C., Calhoun, V. D., \& Saykin, A. J. (2012). A large scale multivariate parallel ICA method reveals novel imaging-genetic relationships for Alzheimer's disease in the ADNI cohort. Neuroimage, 60, 1608-1621. http://doi.org/10. 1016/j.neuroimage.2011.12.076.

Melgani, F., \& Bruzzone, L. (2004). Classification of hyperspectral remote sensing images with support vector machines. IEEE Transactions on Geoscience and Remote Sensing, 42, 1778-1790. http://doi.org/10.1109/ TGRS.2004.831865. 
Messina, N., Wish, E., \& Nemes, S. (2000). Predictors of treatment outcomes in men and women admitted to a therapeutic community. The American Journal of Drug and Alcohol Abuse, 26, 207-227. http://doi.org/10.1081/ ada-100100601.

Mete, M., Sakoglu, U., Spence, J. S., Devous, M. D., Harris, T. S., \& Adinoff, B. (2016). Successful classification of cocaine dependence using brain imaging: A generalizable machine learning approach. BMC Bioinformatics, 17, 49-61. http://doi.org/10.1186/s12859-016-1218-z.

Meyer-Lindenberg, A. (2009). Neural connectivity as an intermediate phenotype: brain networks under genetic control. Human Brain Mapping, 30, 1938-1946. http://doi.org/10.1002/hbm.20639.

Moradi, E., Pepe, A., Gaser, C., Huttunen, H., Tohka, J., \& Initiative, A. D. N. (2015). Machine learning framework for early MRI-based Alzheimer's conversion prediction in MCI subjects. Neuroimage, 104, 398-412. http://doi. org/10.1016/j.neuroimage.2014.10.002.

Nguyen-Louie, T. T., Courtney, K. E., Squeglia, L. M., Bagot, K., Eberson, S., Migliorini, R., \& Pulido, C. (2018). Prospective changes in neural alcohol cue reactivity in at-risk adolescents. Brain Imaging and Behavior, 12, 931-941. http://doi.org/10.1007/s11682-017-9757-0.

Oosterhof, N. N., Connolly, A. C., \& Haxby, J. V. (2016). CoSMoMVPA: Multi-modal multivariate pattern analysis of neuroimaging data in Matlab/GNU Octave. Frontiers in Neuroinformatics, 10, 1-27. http://doi. org/10.3389/fninf.2016.00027.

OuYang, X., Chen, K., Yao, L., Hu, B., Wu, X., Ye, Q., \& Guo, X. (2015). Simultaneous changes in gray matter volume and white matter fractional anisotropy in Alzheimer's disease revealed by multimodal CCA and joint ICA. Neuroscience, 301, 553-562. http://doi.org/10.1016/j.neuroscience. 2015.06.031

Pannunzi, M., Hindriks, R., Bettinardi, R. G., Wenger, E., Lisofsky, N., Martensson, J., ... Deco, G. (2017). Resting-state fMRI correlations: From link-wise unreliability to whole brain stability. Neuroimage, 157, 250-262. http://doi.org/10.1016/j.neuroimage.2017.06.006.

Pariyadath, V., Stein, E. A., \& Ross, T. J. (2014). Machine learning classification of resting state functional connectivity predicts smoking status. Frontiers in Human Neuroscience, 8, 1-10. http://doi.org/10.3389/fnhum. 2014.00425

Park, S., Zhang, Y., Kwon, D., Zhao, Q., Zahr, N., Pfefferbaum, A., \& Pohl, K. (2018). Alcohol use effects on adolescent brain development revealed by simultaneously removing confounding factors, identifying morphometric patterns, and classifying individuals. Scientific Reports, 8, 1-14. http://doi. org/10.1038/s41598-018-26627-7.

Patrick, C.J., Fowles, D.C., \& Krueger, R.F. (2009). Triarchic conceptualization of psychopathy: Developmental origins of disinhibition, boldness, and meanness. Developmental and Psychopathology, 21, 913-938. http://doi.org/ 10.1017/S0954579409000492.

Paulus, M. P., Kuplicki, R., \& Yeh, H.-W. (2019). Machine learning and brain imaging: Opportunities and challenges. Trends in Neurosciences, 42, 659-661. http://doi.org/10.1016/j.tins.2019.07.007.

Pedregosa, F., Varoquaux, Ga"el, Gramfort, A., Michel, V., Thirion, B., ... Grisel, O. (2011). Scikit-learn: Machine learning in Python. Journal of Machine Learning Research, 12, 2825-2830.

Pellegrini, E., Ballerini, L., Hernandez, M. del C. V., Chappell, F. M., González-Castro, V., Anblagan, D., \& Pernet, C. (2018). Machine learning of neuroimaging for assisted diagnosis of cognitive impairment and dementia: A systematic review. Alzheimer's \& Dementia: Diagnosis, Assessment \& Disease Monitoring, 10, 519-535. http://doi.org/10.1016/j.dadm. 2018.07.004.

Peng, Y., Zhang, X., Li, Y., Su, Q., Wang, S., Liu, F., Yu, C., \& Liang, M. (2020). MVPANI: A toolkit with friendly graphical user interface for multivariate pattern analysis of neuroimaging data. Frontiers in Neuroscience, 14, 1-16. http://doi.org/10.3389/fnins.2020.00545.

Perkins, E. R., Latzman, R. D., \& Patrick, C. J. (2019). Interfacing neural constructs with the Hierarchical Taxonomy of Psychopathology: 'Why'and 'how.'. Personality and Mental Health, 14, 106-122. http://doi.org/10. 1002/pmh.1460.

Rashid, B., Arbabshirani, M. R., Damaraju, E., Cetin, M. S., Miller, R., Pearlson, G. D., \& Calhoun, V. D. (2016). Classification of schizophrenia and bipolar patients using static and dynamic resting-state fMRI brain connectivity. Neuroimage, 134, 645-657. http://doi.org/10.1016/j. neuroimage.2016.04.051

Reed, G. M. (2018). Progress in developing a classification of personality disorders for ICD-11. World Psychiatry, 17, 227-229. http://doi.org/10.1002/ wps.20533.

Regier, D. A., Narrow, W. E., Clarke, D. E., Kraemer, H. C., Kuramoto, S. J., Kuhl, E. A., \& Kupfer, D. J. (2013). DSM-5 field trials in the United States and Canada, Part II: Test-retest reliability of selected categorical diagnoses. American Journal of Psychiatry, 170, 59-70. http://doi.org/10.1176/appi.ajp. 2012.12070999.

Ruan, H., Zhou, J., Luo, Q., Robert, G., Desrivières, S., Quinlan, E., \& Feng, J. (2019). Adolescent binge drinking disrupts normal trajectories of brain functional organization and personality maturation. NeuroImage: Clinical, 22, 110. http://doi.org/10.1016/j.nicl.2019.101804.

Ruiz, F. J. R., Valera, I., Blanco, C., \& Perez-Cruz, F. (2014). Bayesian nonparametric comorbidity analysis of psychiatric disorders. The Journal of Machine Learning Research, 15, 1215-1247.

Rutledge, R. B., Chekroud, A. M., \& Huys, Q. J. M. (2019). Machine learning and big data in psychiatry: Toward clinical applications. Current Opinion in Neurobiology, 55, 152-159. http://doi.org/10.1016/j.conb.2019.02.006.

Sakoglu, U., Mete, M., Esquivel, J., Rubia, K., Briggs, R., \& Adinoff, B. (2019). Classification of cocaine-dependent participants with dynamic functional connectivity from functional magnetic resonance imaging data. Journal of Neuroscience Research, 97, 790-803. http://doi.org/10.1002/jnr.24421.

Sato, J. R., de Oliveira-Souza, R., Thomaz, C. E., Basílio, R., Bramati, I. E., Amaro E. Jr, \& Moll, J. (2011). Identification of psychopathic individuals using pattern classification of MRI images. Social Neuroscience, 6, 627639. http://doi.org/10.1080/17470919.2011.562687.

Schmitt, W. A., \& Newman, J. P. (1999). Are all psychopathic individuals lowanxious? Journal of Abnormal Psychology, 108, 353. http://doi.org/10.1037/ 0021-843x.108.2.353

Schrouff, J, Rosa, MJ, Rondina, JM, Marquand, AF, Chu, C, Ashburner, J, \& Mourao-Miranda, J. (2013). PRoNTo: Pattern Recognition for Neuroimaging Toolbox. Neuroinformatics, 11, 319-337. http://doi.org/10. 1007/s12021-013-9178-1.

Schuckit, M. A., Danko, G. P., Smith, T. L., Hesselbrock, V., Kramer, J., \& Bucholz, K. (2003). A 5-year prospective evaluation of DSM-IV alcohol dependence with and without a physiological component. Alcoholism: Clinical and Experimental Research, 27, 818-825. http://doi.org/10.1097/ 01.ALC.0000067980.18461.33.

Sekutowicz, M., Guggenmos, M., Kuitunen-Paul, S., Garbusow, M., Sebold, M., Pelz, P., ... Schmack, K. (2019). Neural response patterns during Pavlovian-to-instrumental transfer predict alcohol relapse and young adult drinking. Biological Psychiatry, 86, 857-863. doi/org/10.1016/j.biopsych. 2019.06.028

Seo, S., Mohr, J., Beck, A., Wüstenberg, T., Heinz, A., \& Obermayer, K. (2015). Predicting the future relapse of alcohol-dependent patients from structural and functional brain images. Addiction Biology, 20, 1042-1055. http://doi.org/10.1111/adb.12302.

Shen, H., Wang, L., Liu, Y., \& Hu, D. (2010). Discriminative analysis of resting-state functional connectivity patterns of schizophrenia using low dimensional embedding of fMRI. NeuroImage, 49, 3110-3121. http://doi.org/10. 1016/j.neuroimage.2009.11.011.

Shepherd, J. P., Shepherd, I., Newcombe, R. G., \& Farrington, D. (2009). Impact of antisocial lifestyle on health: Chronic disability and death by middle age. Journal of Public Health, 31, 506-511. http://doi.org/10.1093/ pubmed/fdp054.

Simard, I., Denomme, W. J., \& Shane, M. S. (2021). Altered power spectra in antisocial males during rest as a function of cocaine dependence: A network analysis. Psychiatry Research: Neuroimaging, 309, 111235. http://doi.org/10. 1016/j.pscychresns.2020.111235.

Skeem, J., Johansson, P., Andershed, H., Kerr, M., \& Louden, J. E. (2007). Two subtypes of psychopathic violent offenders that parallel primary and secondary variants. Journal of Abnormal Psychology, 116, 395-409. http:// doi.org/10.1037/0021-843X.116.2.395.

Smith, S. S., \& Newman, J. P. (1990). Alcohol and drug abuse-dependence disorders in psychopathic and nonpsychopathic criminal offenders. Journal of Abnormal Psychology, 99, 430-439. http://doi.org/10.1037//0021-843x.99.4.430. 
Smitha, K. A., Akhil Raja, K., Arun, K. M., Rajesh, P. G., Thomas, B., Kapilamoorthy, T. R., \& Kesavadas, C. (2017). Resting state fMRI: A review on methods in resting state connectivity analysis and resting state networks. The Neuroradiology Journal, 30, 305-317. http://doi.org/10.1177/19714 00917697342.

Sonnenburg, S., Strathmann, H., Lisitsyn, S., Gal, V., Iglesias, J.G., Lin, W., ... Frank, V. (2010). The SHOGUN machine learning toolbox. Journal of Machine Learning Research, 11, 1799-1802.

Spechler, P., Allgaier, N., Chaarani, B., Whelan, R., Watts, R., Orr, C., \& Garavan, H. (2019). The initiation of cannabis use in adolescence is predicted by sex-specific psychosocial and neurobiological features. European Journal of Neuroscience, 50, 1-23. http://doi.org/10.1111/ejn.13989.

Squeglia, L., Ball, T., Jacobus, J., Brumback, T., McKenna, B., Nguyen-Louie, T., \& Tapert, S. (2017). Neural predictors of initiating alcohol use during adolescence. The American Journal of Psychiatry, 174, 172-185. http://doi. org/10.1176/appi.ajp.2016.15121587.

Steele, V., Rao, V., Calhoun, V., \& Kiehl, K. (2017). Machine learning of structural magnetic resonance imaging predicts psychopathic traits in adolescent offenders. NeuroImage, 145, 265-273. http://doi.org/10.1016/j.neuroimage. 2015.12.013.

Steele, V. R., Claus, E. D., Aharoni, E., Vincent, G. M., Calhoun, V. D., \& Kiehl, K. A. (2015). Multimodal imaging measures predict rearrest. Frontiers in Human Neuroscience, 9, 1-13. http://doi.org/10.3389/fnhum. 2015.00425 .

Steele, V. R., Fink, B. C., Maurer, J. M., Arbabshirani, M. R., Wilber, C. H., Jaffe, A. J., \& Clark, V. P. (2014). Brain potentials measured during a $\mathrm{Go} /$ NoGo task predict completion of substance abuse treatment. Biological Psychiatry, 76, 75-83. http://doi.org/10.1016/j.biopsych.2013.09.030.

Steele, V. R., Maurer, J. M., Arbabshirani, M. R., Claus, E. D., Fink, B. C., Rao, V., \& Kiehl, K. A. (2018). Machine learning of functional magnetic resonance imaging network connectivity predicts substance abuse treatment completion. Biological Psychiatry. Cognitive Neuroscience and Neuroimaging, 3, 141-149. http://doi.org/10.1016/j.bpsc.2017.07.003.

Sui, J., Pearlson, G., Caprihan, A., Adali, T., Kiehl, K. A., Liu, J., \& Calhoun, V. D. (2011). Discriminating schizophrenia and bipolar disorder by fusing fMRI and DTI in a multimodal CCA+ joint ICA model. Neuroimage, 57, 839-855. http://doi.org/10.1016/j.neuroimage.2011.05.055.

Świątkowski, W., \& Dompnier, B. (2017). Replicability crisis in social psychology: Looking at the past to find new pathways for the future. International Review of Social Psychology, 30, 111-124. http://doi.org/10.5334/irsp.66.

Tang, Y., Jiang, W., Liao, J., Wang, W., \& Luo, A. (2013a). Identifying individuals with antisocial personality disorder using resting-state FMRI. PloS One, 8, 1-9. http://doi.org/10.1371/journal.pone.0060652.

Tang, Y., Liu, L., Chen, J., Liao, J., Hu, D., \& Wang, W. (2013b). Altered spontaneous activity in antisocial personality disorder revealed by regional homogeneity. Neuroreport, 24, 590-595. http://doi.org/10.1097/WNR. ob013e3283627993.

Tang, Y., Meng, L. I., Wan, C., Liu, Z, Liao, W, Yan, X., Wang, X., Tang, B., \& Guo, J. F. (2017). Identifying the presence of Parkinson's disease using low-frequency fluctuations in BOLD signals. Neuroscience Letters, 645, 1-6. http://doi.org/10.1016/j.neulet.2017.02.056.

Thompson, P. (2019). Enigma, big data, and neuroimaging genetics in 50,000 people from 35 countries: Challenges and lessons learned. European Neuropsychopharmacology, 29, S769-S770. http://doi.org/10.1016/j.euro neuro.2017.06.131.

Tursich, M., Ros, T., Frewen, P. A., Kluetsch, R. C., Calhoun, V. D., \& Lanius, R. A. (2015). Distinct intrinsic network connectivity patterns of post-traumatic stress disorder symptom clusters. Acta Psychiatrica Scandinavica, 132, 29-38. http://doi.org/10.1111/acps.12387.

Valdes-Sosa, P.A., Sanchez-Bornot, J.M., Sotero, R.C., Iturria-Medina, Y., Aleman-Gomez, Y., Bosch-Bayard, J., \& Ozaki, T. (2009). Model driven EEG/fMRI fusion of brain oscillations. Human Brain Mapping, 30, 27012721. http://doi.org/10.1002/hbm.20704.

Van Dam, N. T., O'Connor, D., Marcelle, E. T., Ho, E. J., Craddock, R. C., Tobe, R. H., \& Leventhal, B. L. (2017). Data-driven phenotypic categorization for neurobiological analyses: Beyond DSM-5 labels. Biological Psychiatry, 81, 484-494. http://doi.org/10.1016/j.biopsych.2016.06.027.
Vieira, S., Pinaya, W. H. L., \& Mechelli, A. (2017). Using deep learning to investigate the neuroimaging correlates of psychiatric and neurological disorders: Methods and applications. Neuroscience \& Biobehavioral Reviews, 74, 58-75. http://doi.org/10.1016/j.neubiorev.2017.01.002.

Volkow, N. D., Hitzemann, R., Wang, G.-J., Fowler, J. S., Burr, G., Pascani, K., .. Wolf, A. P. (1992). Decreased brain metabolism in neurologically intact healthy alcoholics. American Journal of Psychiatry, 149, 1016-1022. http://doi.org/10.1176/ajp.149.8.1016.

Volkow, N. D., Koob, G. F., \& McLellan, A. T. (2016). Neurobiologic advances from the brain disease model of addiction. New England Journal of Medicine, 374, 363-371. http://doi.org/10.1056/NEJMra1511480.

Waller, L., Brovkin, A., Dorfschmidt, L., Bzdok, D., Walter, H., \& Kruschwitz, J. D. (2018). GraphVar 2.0: A user-friendly toolbox for machine learning on functional connectivity measures. Journal of Neuroscience Methods, 308, 21-33. http://doi.org/10.1016/j.jneumeth.2018.07.001.

Walter, M., Alizadeh, S., Jamalabadi, H., Lueken, U., Dannlowski, U., Walter, H., \& Dwyer, D. B. (2019). Translational machine learning for psychiatric neuroimaging. Progress in Neuro-Psychopharmacology and Biological Psychiatry, 91, 113-121. http://doi.org/10.1016/J.PNPBP.2018.09.014.

Wang, S., Zhang, R., Deng, Y., Chen, K., Xiao, D., Peng, P., \& Jiang, T. (2018). Discrimination of smoking status by MRI based on deep learning method. Quantitative Imaging in Medicine and Surgery, 8, 1113-1120. http://doi.org/10.21037/qims.2018.12.04.

Wei, L., Wu, G., Bi, M., \& Baeken, C. (2021). Effective connectivitypredicts cognitive empathy in cocaine addiction: a spectral dynamic causal modeling study. Brain Imaging and Behavior, 15, 1553-1561. https://doi.org/10.1007/ s11682-020-00354-y.

Wetherill, R. R., Rao, H., Hager, N., Wang, J., Franklin, T. R., \& Fan, Y. (2018). Classifying and characterizing nicotine use disorder with high accuracy using machine learning and resting-state fMRI. Biological Psychiatry, 24, 811-821. http://doi.org/10.1111/adb.12644.

Whelan, R., Watts, R., Orr, C. A., Althoff, R. R., Artiges, E., Banaschewski, T., \& Carvalho, F. M. (2014). Neuropsychosocial profiles of current and future adolescent alcohol misusers. Nature, 512, 185-189. http://doi.org/ 10.1038 /nature13402.

Widiger, T. A. (1992). Categorical versus dimensional classification: Implications from and for research. Journal of Personality Disorders, 6, 287-300. http://doi.org/10.1521/pedi.1992.6.4.287.

Wium-Andersen, I. K., Vinberg, M., Kessing, L. V., \& McIntyre, R. S. (2017). Personalized medicine in psychiatry. Nordic Journal of Psychiatry, 71, 12-19. http://doi.org/10.1080/08039488.2016.1216163.

Woo, C.-W., Chang, L. J., Lindquist, M. A., \& Wager, T. D. (2017). Building better biomarkers: Brain models in translational neuroimaging. Nature Neuroscience, 20, 365-377. http://doi.org/10.1038/nn.4478.

Yildirim, B. O., \& Derksen, J. J. L. (2015). Clarifying the heterogeneity in psychopathic samples: Towards a new continuum of primary and secondary psychopathy. Aggression and Violent Behavior, 24, 9-41. http://doi.org/10. 1016/j.avb.2015.05.001.

Yip, S., Scheinost, D., Potenza, M., \& Carroll, K. (2019). Connectome-based prediction of cocaine abstinence. The American Journal of Psychiatry, 176, 156-164. http://doi.org/10.1176/appi.ajp.2018.17101147.

Yip, S. W., Worhunsky, P. D., Xu, J., Morie, K. P., Constable, R. T., Malison, R. T., \& Potenza, M. N. (2018). Gray-matter relationships to diagnostic and transdiagnostic features of drug and behavioral addictions. Addiction Biology, 23, 394-402. http://doi.org/10.1111/adb.12492.

Yu, R., Zhao, L., \& Lu, L. (2011). Regional grey and white matter changes in heavy male smokers. PloS One, 6, 1-7. http://doi.org/10.1371/journal.pone.0027440.

Zald, D. H., \& Lahey, B. B. (2017). Implications of the hierarchical structure of psychopathology for psychiatric neuroimaging. Biological Psychiatry: Cognitive Neuroscience and Neuroimaging, 2, 310-317. http://doi.org/10. 1016/j.bpsc.2017.02.003.

Zeng, L., Shen, H., Liu, L., Wang, L., Li, B., Fang, P., \& Hu, D. (2012). Identification major depression using whole brain functional connectivity: A multivariate pattern analysis. Brain, 135, 1498-1507. http://doi.org/10. 1093/brain/aws059.

Zhang, J., Cao, W., Wang, M., Wang, N., Yao, S., \& Huang, B. (2019). Multivoxel pattern analysis of structural MRI in children and adolescents 
with conduct disorder. Brain Imaging and Behavior, 13, 1273-1280. http:// doi.org/10.1007/s11682-018-9953-6.

Zhang, J., Liu, W., Zhang, J., Wu, Q., Gao, Y., Jiang, Y., \& Huang, B. (2018). Distinguishing adolescents with conduct disorder from typically developing youngsters based on pattern classification of brain structural MRI. Frontiers in Human Neuroscience, 12, 1-9. http://doi.org/10.3389/ fnhum.2018.00152.

Zhang, S., Hu, S., Sinha, R., Potenza, M., Malison, R., \& Li, C. (2016). Cocaine dependence and thalamic functional connectivity: A multivariate pattern analysis. NeuroImage: Clinical, 12, 348-358. http://doi.org/10.1016/j.nicl. 2016.08.006.

Zhang, X., Mormino, E. C., Sun, N., Sperling, R. A., Sabuncu, M. R., Yeo, B. T. T., \& Initiative, A. D. N. (2016). Bayesian model reveals latent atrophy factors with dissociable cognitive trajectories in Alzheimer's disease. Proceedings of the National Academy of Sciences, 113, E6535-E6544. http://doi.org/10.1073/pnas.1611073113

Zhang, Y., Tian, J., Yuan, K., Liu, P., Zhuo, L., Qin, W., \& Klahr, N. J. (2011). Distinct resting-state brain activities in heroin-dependent individuals. Brain Research, 1402, 46-53. http://doi.org/10.1016/j.brainres.2011.05.054.
Zhao, M., Liu, J., Cai, W., Li, J., Zhu, X., Yu, D., \& Yuan, K. (2019). Support vector machine based classification of smokers and nonsmokers using diffusion tensor imaging. Brain Imaging and Behavior, 14, 2242-2250. http://doi. org/10.1007/s11682-019-00176-7.

Zhao, X., Rangaprakash, D., Yuan, B., Denney, T. S. Jr, Katz, J., Dretsch, M. N., \& Deshpande, G. (2018). Investigating the correspondence of clinical diagnostic grouping with underlying neurobiological and phenotypic clusters using unsupervised machine learning. Frontiers in Applied Mathematics and Statistics, 4, 1-27. http://doi.org/10.3389/fams.2018. 00025.

Zhu, X., Du, X., Kerich, M., Lohoff, F., \& Momenan, R. (2018). Random forest based classification of alcohol dependence patients and healthy controls using resting s tate MRI. Neuroscience Letters, 676, 27-33. http://doi.org/ 10.1016/j.neulet.2018.04.007.

Zilverstand, A., Curtin, P., Parvaz, M., Liston, C., Alia-Klein, N., \& Goldstein, R. (2018). O38. Resting-state connectivity defines neurobiological subtypes underlying different cognitive-emotional profiles in cocaine addiction. Biological Psychiatry, 83, S124-S124. http://doi.org/10.1016/j. biopsych.2018.02.325. 